\title{
La ciencia lo dijo. Relaciones entre ciencia, razón y fe
}

\author{
IGNACIO SOLS \\ Facultad de Matemáticas \\ Universidad Complutense de Madrid \\ isols@mat.ucm.es
}

Resumen. Tras una descripción del método usado en las matemáticas y en las ciencias experimentales, breve pero suficiente para marcar sus límites con la reflexión filosófica y teológica, recuerdo las relaciones de convivencia armónica y apoyo mutuo entre estos tres ámbitos, y también las ocasiones históricas en que esos límites han sido sobrepasados. Y tras una visión fugaz de la imagen del mundo - materia inerte y materia viva- que nos presenta la ciencia actualmente establecida, recuerdo los principales puntos de oposición que a la fe se han puesto desde la ciencia, en ocasiones ciencia tan sólo prometida. Muestro que la ciencia actual está en armonía con la fe y que se trata de oposición desde la filosofía materialista de algunos divulgadores, más bien que de oposición desde datos de la ciencia hoy establecida. Finalmente, argumentamos que el hilemorfismo aristotélico-tomista, que pone forma en la materia, es más apto para el diálogo con la ciencia actual que las filosofías de tipo kantiano que ponen forma tan sólo en nuestro conocimiento o en nuestras teorías científicas.

Palabras clave: ciencia y fe; epistemología; hilemorfismo.

Abstract. Science Said. Relationships between Science, Reason and Faith. After a description of the method of mathematics and empirical sciences, brief but explicit enough to show their limits with philosophical and theological reflection, I comment the harmonic relations of mutual help among them, and also, unfortunately, the historical occasions in which these limits have been trespassed. And after a fast view of the image of the world-matter and life-presented to us by nowadays established science, I recall the 
main items of opposition to faith posed by science, although sometimes just promised science. I show that today's science is in complete harmony with faith and that these items only show the opposition with faith of the materialistic philosophical points of view of some of the divulgators, not really opposition of established science. Finally we discuss that Aristotelian hylomorphism, posing form in matter, is more suited to dialog with present science than philosophies of Kantian inspiration posing form only in our knowledge or in our scientific theories.

Keywords: science and religion; epistemology; hylomorphism.

\section{Introducción}

Relaciones entre ciencia, razón y fe es el tema que se me propuso para una conferencia en el pasado mes de Febrero en el IESE de Barcelona, institución a la que agradezco su invitación pues me ha brindó la oportunidad de poner mis tierras en orden en esta materia. El presente artículo recoge lo expuesto en aquella conferencia ${ }^{1}$.

En la segunda lección de su Curso de Filosofía Positiva, Auguste Compte saldó la relación entre estos tres ámbitos en que el conocimiento de la humanidad sigue las etapas del conocimiento de un hombre. En la etapa infantil, el hombre que todo lo ignora encuentra explicaciones mitológicas para todo, y esta sería la etapa religiosa de la humanidad. Luego, el hombre ya joven se hace preguntas de calado, queriendo comprender el porqué de cuanto le rodea, y ésta correspondería a la etapa filosófica de la humanidad. Finalmente, el hombre maduro es pragmático y se da cuenta de que esas preguntas no tienen respuesta, y de que no está su inteligencia para responder a ellas sino para entender la naturaleza lo suficiente para ponerla a su servicio y procurarse una vida más cómoda; etapa científica del hombre y de la humanidad.

1 El lector que sólo busque en este artículo unos criterios con los que dar respuesta a los problemas que pretende crear a la fe cierta divulgación de la ciencia más bien reciente, puede adelgazarlo drásticamente leyendo sólo la penúltima sección: “¿Es la ciencia establecida problemática para la fe?” (Para ello, se supone, en parte, que tiene una cierta formación científica, de modo que ha podido saltarse la sección anterior, pura divulgación). 
Este planteamiento positivista ha tenido una enorme influencia, en parte porque es un esquema fácil de comprender, con el atractivo de la simplicidad. Dejando de lado, de momento, las causas filosóficas que han llevado a este planteamiento, reseñemos tan sólo la enorme influencia que ha tenido y tiene en el momento actual, hasta el punto de que su implícito agnosticismo ha venido a sustituir, en la moda intelectual, al ateísmo materialista del pensamiento marxista del siglo XX (mayo, sí, de 1968). "La religión está siendo suplida por la ciencia” parece ser el mensaje subliminal que nos llega por los medios, en la idea de que la religión se fundamenta en lo que ignoramos y teme el día de luz que haya de traer la ciencia, día en que no ignoremos nada, y en que la religión haya quedado sin fundamento. Pero en la práctica lo que ocurre es que es la filosofía la que está siendo suplida por la ciencia, pues al haber despreciado el positivismo los más hondos interrogantes del hombre como preguntas sin sentido, y al no poder el hombre dejar de hacerse esas preguntas, disfraza esas cuestiones filosóficas de cuestiones científicas. Pero la ciencia, por su propio método, no puede responder a ellas. Así por ejemplo, las insoslayables preguntas filosóficas por la existencia de Dios, o por el espíritu en el hombre, o sobre la humana libertad y consiguiente responsabilidad moral, están ocultas tras el interés por la teoría del Big-Bang, o por la teoría de máquinas en informática, o por el principio de incertidumbre en mecánica cuántica, teorías científicas cuyo método no está diseñado para responder a esas preguntas.

Aparte, pues, de la refutación histórica de este esquema simplista por el hecho de que gran parte de los padres de la ciencia no vieron en ella incompatibilidad alguna con su sensibilidad religiosa, y de hecho bastantes de ellos fueron además filósofos, importa una refutación sustantiva del positivismo por un actualizado discurso del método que distinga bien estos tres ámbitos, algo que brevemente esbozaré en la primera sección. En la segunda trataré algunos ejemplos de extralimitación e invasión entre estos ámbitos. La tercera sección tiene carácter divulgativo y es preparatoria hacia la cuarta, recordando en breve pincelada la imagen del mundo que en la actualidad nos presenta la ciencia experimental. La cuarta sección intenta establecer las posturas filosóficas que cerrarían el paso a la 
transcendencia religiosa, preguntándonos en ella si algún dato en nuestra actual visión científica del mundo, recordada en la sección anterior, podría servir de soporte a tales posturas. Termino esta sección con una crítica de la filosofía oculta en alguna divulgación científica reciente, que es quizá lo que el lector esperaba bajo este título. En la última sección, ya en positivo, señalo algunas consecuencias filosóficas que parecen desprenderse de la imagen del mundo que hoy nos presenta la ciencia, y me pronuncio sobre el sistema filosófico que me parece más compatible con esas consecuencias y por tanto con mayor capacidad de diálogo con esa imagen científica.

\section{El método científico ${ }^{2}$}

En esta sección trataré someramente de la reflexión filosófica y teológica, y en detalle sobre el método científico. Será el mínimo suficiente para dejar clara su distinción. La reflexión filosófica nos interesará en su sentido más amplio, del cual la filosofía académica no es sino su formalización: la búsqueda de verdad que hay en todo hombre. Esas preguntas profundas que, ordinariamente no formalizadas, todo hombre se plantea en algún momento: qué puedo saber, qué debo hacer, qué me es permitido esperar (como lo pone Kant). Un hombre corriente está filosofando cuando dice “de la nada, nada sale", modo no despreciable de enunciar el principio de causalidad, o cuando dice "algo tiene que haber", resumen bastante convincente de las vías de Santo Tomás. Hablando pues de filosofía de este modo amplio, no tendría sentido describir su método, sino más bien tratar

2 Por la palabra "científico", nos referimos aquí a ciencias experimentales, es decir las que suponen un "facere", una actividad experimental. Soy impropio, cuando, llevado de la costumbre, utilizo para ámbito tan restringido la palabra "ciencia" que en realidad tiene un sentido más amplio, pues "Scientia”, del verbo "scire”, es todo saber, incluidas las ciencias humanas y, por supuesto, la filosofía y la teología. En cambio se da una ampliación de significado en sentido contrario cuando el cardinal Ratzinger, en su discurso en la Sorbonne sobre la encíclica Fides et ratio, el 27 de noviembre de 1999, denuncia que sea calificada como no científica la cuestión de la verdad. Tiene razón en cuanto que se trata, en efecto, de una cuestión filosófica y por tanto de verdadero "scire", verdadera "ciencia", pero creo que no tiene razón al usar en este contexto la palabra "científico", cuyo sentido propio se refiere a la ciencia experimental. 
de sus presupuestos. Si la filosofía es búsqueda de verdad, el presupuesto de esta búsqueda es que la verdad existe, es decir que existe una realidad y una razón de que sea como es -principio de racionalidad-, y que podemos conocer, al menos en parte, esa verdad. La negación de esto sería el escepticismo digamos académico, pues el escepticismo práctico no se da. (No he conocido a nadie que pretenda que nada de lo que él dice sea verdad, o que se arroje al fuego porque dude de su existencia). El tipo de pensamiento que este escepticismo origina no es propiamente filosofía -búsqueda de la verdad, como su nombre indica- sino más bien pensamiento que niega la filosofía y ordinariamente la sustituye por una praxis (no explicar el mundo, sino transformarlo).

Se trata pues de una búsqueda de la verdad con sólo la razón. En teología, en cambio, el hombre cuenta además con la palabra revelada, que para quien esto escribe se da en el cristianismo, en Jesucristo. El beato Newman decía que la religión es natural (en efecto, no se ha dado ningún pueblo sin religión); que el ateísmo es pues antinatural (como no es natural ser ciego, sino ver, aunque haya ciegos de nacimiento); y que el cristianismo es sobrenatural, pues se ha dado en él palabra revelada (es decir que Dios se ha manifestado al hombre precisamente por donde el hombre lo buscaba, en la religión). El papel ahí de la razón es el "intellige ut credas” de S. Agustín, mostrar la razonabilidad de la fe (no demostrar la fe, lo que sería contradictorio y sería olvidar que la fe es don del Espíritu Santo); y es también el "crede ut intelligas”, también de S. Agustín, es decir que fiándonos (eso significa "fe”) de la Palabra revelada, podemos con ayuda de nuestra razón profundizar en ella, y, a partir de ella, comprender mejor el sentido último de la realidad que nos rodea y de nuestra propia realidad.

La distinción de estos dos ámbitos con el ámbito científico quedará clara con sólo una breve descripción de su método, algo a lo que dedicaré esta primera sección, y empezando por el método matemático, ya que el método de las ciencias experimentales intentará emular, siempre que pueda, el método axiomático de las matemáticas. El paradigma de este método fue desde finales del siglo IV a. C. la disposición de los Elementos de Euclides donde la geometría del plano -después del espacio- era de- 
rivada por el razonamiento lógico a partir de cinco axiomas, tales como "por dos puntos distintos pasa una y sólo una recta". (De hecho, en sus deducciones, Euclides utilizó sin darse cuenta concesiones a la intuición que no había axiomatizado, y la ampliación de sus axiomas para dotar los Elementos de rigor demostrativo, según los cánones actuales, fue llevada a cabo por David Hilbert en sus "Grundlagen der Geometrie" (Hilbert 1903)). Este método axiomático-deductivo fue inspiración, como veremos, para otras ciencias y al final para todas las matemáticas. En la década de los ochenta del siglo XIX, Cantor había creado una teoría de conjuntos para fundamentar su teoría de cardinales (números no necesariamente finitos), pero pronto se vio que servían de hecho para fundamentar todas las matemáticas. Así pues, cuando Zermelo y Fraenkel fueron capaces de deducir, como "teoría lógica", toda la teoría de conjuntos de sólo nueve axiomas, a los que luego se añadió el axioma de elección y la hipótesis del continuo, lo que hicieron en realidad fue deducir todas las matemáticas de esos axiomas. Una teoría lógica (axiomática de primer orden) viene dada por unos símbolos en que expresar las proposiciones de la teoría, entre los cuales han de figurar los símbolos lógicos “y”, "o”, "negación”, "implicación”, "existe un”, "para todo”, y unas reglas de deducción lógica de unas proposiciones a partir de otras (reglas que formalizan la lógica deductiva aristotélico-tomista). Los teoremas de la teoría son las proposiciones deducibles de esta manera de unas proposiciones elegidas como "axiomas" de la teoría, y así por ejemplo los teoremas de las matemáticas, es decir de la teoría de conjuntos, son los que se deducen según estas reglas de la lógica de aquellos once axiomas (o esquemas de axioma, un tecnicismo). Es un importante tema debatido si las matemáticas son o no algo más que una mera teoría lógica de primer orden, pero lo que no es opinión sino hecho, hoy por todos admitido, es que todas las matemáticas hasta hoy escritas, antes y después de esta formalización, son deducibles en lógica de primer orden de esos once axiomas (es decir que todas las demostraciones matemáticas de que disponemos se podrían reescribir con sólo esos símbolos y reglas deductivas, algo que, por cierto, resultaría muy aburrido). Al comprender las matemáticas como una teoría lógica hemos podido 
comprender también sus límites (recordemos a Kurt Gödel): no todas las proposiciones verdaderas acerca de los números son deducibles de estos axiomas (ni de ninguna ampliación de ellos mediante un número finito de nuevos axiomas); no existe ningún algoritmo para saber si una proposición dada en el lenguaje de esos mismos símbolos, es o no teorema, es decir deducible de los axiomas (no hay una máquina o programa "oráculo" que pueda decidir esta cuestión); y no es teorema de la propia teoría, es decir de las matemáticas, aquél que afirma que la teoría es consistente, donde "consistente" significa que no haya una proposición que sea teorema de la teoría y a la vez lo sea también su negación.

El método axiomático-deductivo que hoy, formalizado o no, concebimos para todas las matemáticas, y que desde la época de los griegos se concebía ya para esa parte de la matemática que es la geometría euclídea, ha ejercido una cierta fascinación sobre otros ámbitos del saber humano. Al hablar en la sección siguiente de las invasiones metodológicas de un campo en otro, trataré de la influencia, que yo entiendo ilegal, del método matemático en la filosofía racionalista. Pero una influencia legal, y ciertamente celebrada, ha tenido el método axiomático en las ciencias experimentales desde el siglo XVII. Ya Fermat, en ese mismo siglo, había comprendido que toda la óptica geométrica era reducible, mediante cálculos matemáticos, a un solo axioma o principio: la luz recorre siempre un camino mínimo. Pero fue en la Mecánica donde este método deductivo fue saludado por primera vez como el propio de la ciencia: había en Mecánica muchas cuestiones disputadas, hasta que Newton fue capaz de deducir matemáticamente las leyes de la mecánica hasta entonces conocidas, y otras leyes nuevas, de tan sólo tres postulados, y en realidad de uno sólo: la variación (derivada temporal) de la cantidad de movimiento (masa por velocidad) de un móvil es igual a la fuerza a él aplicada (es decir, fuerza = masa $\times$ aceleración). Dos siglos más tarde, todas las leyes del electromagnetismo halladas empíricamente a lo largo de un siglo de trabajo aparecían como deducidas matemáticamente de tan sólo cuatro postulados o principios, las leyes de Maxwell. También la termodinámica se convierte en ciencia derivada de unos pocos principios. Y cuando surjan más tarde la relatividad especial, la relatividad general y la 
mecánica cuántica también lo harán como teorías derivadas matemáticamente de unos principios, axiomas o postulados.

Pero en modo alguno la ciencia experimental se reduce a teorías deductivas, es decir derivadas de unos postulados, pues stricto sensu esto sólo se da en física teórica. Sin embargo conviene comprender bien la estructura de una teoría deductiva pues se ha intentado emular, como paradigma, en otros campos del saber.

Aunque la visión de la ciencia de Karl Popper ha sido combatida en aspectos superficiales por otros epistemólogos, ofrece en lo esencial el cuadro de la ciencia experimental hoy comúnmente admitido (Popper 1967) (Thomas Kuhn en su “Estructura de las revoluciones científicas” (Kuhn 2005) sólo protesta el modo en que, según Popper, se abandona una teoría para dejar paso a otra nueva). Karl Popper recuerda que se dan en la ciencia experimental dos fases: La primera, la creación de una base empírica, y la segunda (en las ciencias que pueden llegar a ello) la creación de una teoría deductiva.

En su primera fase, la fase experimental, las proposiciones de la ciencia son particulares, es decir, predicadas de un sujeto singular: "esta muestra de hierro se ha dilatado con el calor”, proposiciones pues que la experiencia ha verificado. Incluso las leyes experimentales que en esta fase se enuncian de forma universal, como "el hierro se dilata con el calor”, es decir proposiciones predicadas de un sujeto universal, son universales sólo en apariencia, pues, en el fondo, su verdadero significado es que "todas las muestras de hierro con las que hasta ahora se ha experimentado se han dilatado con el calor", ya que muchas proposiciones particulares no implican una sola proposición universal. (Al exponer más abajo un punto de vista más personal, diré que estas leyes experimentales son realmente universales si se combinan con la hipótesis de regularidad: "bajo idénticas condiciones, la naturaleza responde siempre del mismo modo". El peaje pagado es entonces que la ley universal así obtenida es, en el fondo, hipotética).

La fase teórica se inicia cuando se postulan unas proposiciones universales, ya sean leyes procedentes de la base experimental o de alguna manera relacionadas con esas leyes experimentales. La teoría científica 
consiste entonces en todas las proposiciones, todas ellas universales, que se deducen con el sólo uso de la lógica -de hecho con el uso de la matemática- de los postulados que se han elegido. Por ser universales las proposiciones de una teoría científica, ésta es experimentalmente falsable, en el sentido de que puede ser mostrada falsa -si lo es- mediante una experiencia. En efecto, basta que una de las proposiciones universales de la teoría falle en una experiencia concreta para que esta proposición, y con ella los postulados que la implican, aparezca como falsa. De hecho la falsabilidad experimental es tomada por Karl Popper como criterio de que nos hallamos ante una teoría científica: que sea falsable y, se sobreentiende, que haya sido "corroborada" por la experiencia, es decir que haya sido sometida a suficiente experimentación sin que nunca haya resultado falsa. Este criterio sirve también en la fase experimental -en la que se hallan la mayoría de las ciencias, no deducidas de unos postulados- en la medida en que se entienden sus leyes experimentales como enunciados universales: estos enunciados no pueden ser verificados mediante uno ni muchos experimentos, pero sí pueden ser mostrados falsos por sólo uno.

Peligroso es el malentendido -aviso del propio Popper- de que la falsabilidad experimental sea criterio no sólo de cientifidad sino de validez de cualquier conocimiento humano. Porque hay más conocimiento humano que el conocimiento meramente científico. Si alguien intenta hacerme creer, por ejemplo, que se ha escrito novela tan maravillosa como el Quijote sacando de un bombo de la lotería las sucesivas letras, espacios en blanco, y signos de puntuación yo sé que no ha sido así, aunque eso no me lo enseñe la biología ni la química ni la física ni la matemática. Y lo sé aunque, matemáticamente, la probabilidad de que haya salido tan maravillosa sucesión de símbolos sea la misma que la de cualquier otra sucesión. O, pasando a la razón práctica, tampoco podrán las diversas disciplinas científicas aportarme ninguna razón para no llevar a la cámara de gas a quienes me parezcan parásitos de la sociedad, y sin embargo hay buenas razones para no hacerlo.

Dicho esto, el lector de menor interés filosófico podrá dar esta sección por terminada y saltar a la siguiente. Pero si le interesa que apliquemos el 
análisis kantiano de los juicios a aquéllos que aparecen en una y otra fase según esta descripción popperiana de la ciencia experimental, le haré ver que ni siquiera en ciencia se dan los juicios sintéticos a priori, los cuales Kant tomaba como condición para que la filosofía tuviera el rigor ya conseguido en la mecánica newtoniana.

Recordemos (Kant 1978) que Immanuel Kant llama a un juicio sintético cuando el predicado dice algo nuevo del sujeto, algo que no aparece por análisis de la misma definición del sujeto, y en caso contrario dice que el juicio es analítico. Y recordemos también que llama a un juicio a posteriori o a priori según se siga de la experiencia o no necesite de ella. Como para Kant, que escribe en pleno éxito de la mecánica newtoniana, es incuestionable que hay ciencia, y ciencia de validez universal, es incuestionable para él que hay juicios sintéticos (aportando conocimiento nuevo) que son a la vez a priori (para que su validez sea universal y no dependa de experiencias particulares). Como el nuevo conocimiento que aportan esos juicios sintéticos no puede proceder de la experiencia por ser a priori, la nueva verdad que contienen debemos extraerla de nuestra propia facultad de conocer, como observada en ella, de donde concluye que existen apriorismos en nuestro conocimiento, y es su descripción lo que se propone en su famosa “Crítica de la Razón Pura”.

Pero veamos si verdaderamente hay juicios sintéticos a priori en la ciencia, tal como ahora la entendemos (después de que hemos comprendido, tras las revoluciones de la Relatividad Especial, Relatividad General y Mecánica Cuántica, que los postulados de Newton eran verdaderamente postulados, afirmaciones hipotéticas). En la fase experimental no se hallan, pues allí todos los juicios son obviamente "a posteriori”. En el momento en que se proponen los postulados, ni siquiera hay juicios, puesto que se trata de principios que no se afirman sino que se postulan (postulare = pedir. Se pide a la audiencia que los admita para dar inicio a las deducciones). Y en la fase de deducción de la teoría científica desde esos postulados, todos los juicios son analíticos pues proceden del análisis de la verdadera definición del objeto bajo estudio en la teoría, que consiste en los postulados de la teoría (el objeto es todo lo que cumpla esos postulados). 
Así pues, como en la fase experimental los juicios son a posteriori, y en la fase deductiva son analíticos, sólo habría juicios sintéticos a priori en ciencia si sus postulados fuesen juicios, es decir verdaderas aserciones acerca de la naturaleza. Pero no lo son, sino que tienen carácter hipotético, pues sólo son un "supongamos...", por tanto no propiamente juicios. Veamos cómo llegamos a formar esas hipótesis en ciencia, es decir cómo de muchas experiencias particulares con un mismo resultado, llegamos a formar una ley universal de carácter hipotético, la cual quizá elijamos como postulado para la deducción de la teoría. Poincaré decía en su obra "La Science et l'Hypothese" (Poincaré 1902) que formamos la ley universal mediante la hibridación de un resultado coincidente en muchas experiencias particulares con dos hipótesis sin las cuales no hay ciencia: la hipótesis de simplicidad y la hipótesis de regularidad. La primera consiste en que proponemos siempre la ley más sencilla como explicación de los hechos observados (ejemplo: al caer en la cuenta de que las posiciones observadas de un planeta están siempre sobre una elipse, proponemos que la trayectoria del planeta es esa elipse, cuando hay otras muchas curvas, aunque más complicadas, que también pasan por esas mismas posiciones). Y la hipótesis de regularidad consiste en que suponemos que la naturaleza responde siempre de un mismo modo bajo idénticas condiciones (modo que puede ser aleatorio, como ocurre en las observaciones de la mecánica cuántica), y por tanto, si hasta ahora siempre se ha obtenido, bajo las mismas condiciones, un mismo resultado, suponemos que así será en el futuro. Esto es lo que decimos al enunciar como ley universal lo que en realidad sólo es el resultado de experiencias particulares. (Personalmente creo que se trata de una sola hipótesis, pues creo que la hipótesis de regularidad se reduce a la de simplicidad: La explicación más simple de que hasta ahora se haya obtenido el mismo resultado no puede ser un increíble cúmulo de casualidades sino que, conozcamos o no la razón, necesariamente tenía que salir, bajo esas condiciones, ese resultado, y por tanto así seguirá ocurriendo en el futuro. Si tengo razón, bien puede decirse que la única hipótesis que hace posible la ciencia es tan natural como el conocimiento mismo, y es casi la definición misma del conocer, puesto 
que comprender algo no es sino encontrar unidad y simplicidad en lo que parecía inconexo y vario) $)^{3}$.

Hay una natural relación armoniosa entre los tres ámbitos brevemente descritos en esta sección. No cabe duda de que puede haberla entre la faceta religiosa y filosófica en un mismo hombre, pues un hombre puede meditar con su entendimiento sobre la razonabilidad de su fe, y puede ahondar con su razón en los misterios de la palabra revelada y la misma filosofía le proporcionará los términos adecuados para poder referirse a ellos (la filosofía griega proporcionó términos muy precisos para referirse, de modo inmune a injerencias extrañas, a las verdades que enseñaba el evangelio cristiano y que eran creídas "ubique et ab omnibus" desde los tiempos apostólicos. Esto se hizo necesario cuando llegó el tiempo de las peligrosas injerencias de otras religiones y filosofías -por ejemplo el maniqueísmo o la filosofía de Plotino- que hubieran podido dar al traste con la fe). Y la religión presta su ayuda al uso natural de la razón, al señalar como posibles desviaciones aquellas posturas filosóficas que cerrarían la puerta al hecho religioso (no me detengo en ejemplos, porque aparecerán en la cuarta sección).

3 No quiero terminar este recuerdo de la descripción popperiana de la ciencia sin decir que yo simpatizaría con quienes reclaman una inyección de hilemorfismo en la presentación popperiana de la ciencia, en la que ven una excesiva influencia de la formación kantiana de Karl Popper. Los postulados, y en consecuencia la teoría de ellos derivada, deberían ser tenidos por verdadero conocimiento de la naturaleza en el sentido de que la forma-en-los-postulados, y por tanto en la teoría de ellos derivada, sería una aproximación, aunque provisional y dependiente de los datos hasta el momento disponibles, de esa forma-en-la-naturaleza que pone el hilemorfismo, o más bien a un grado o nivel de esa forma (la física de partículas, la física del estado sólido -nivel atómico y molecular-, la química orgánica y la zoología estudiarían a distintos niveles aquella forma que la consideración hilemórfica de la naturaleza pone en un jilguero). La recuperación de la causa formal, es decir, de la forma como causa del ser o forma-en-el -ser, y no sólo forma en los postulados y teorías con que la estudiamos, es decir la verdadera superación filosófica del materialismo, me parece una exigencia filosófica no sólo para una adecuada epistemología de la reciente informática y de la aún más reciente informática de la biología, sino de toda epistemología, si es que ha de atender al conocimiento científico como verdadero conocimiento de la naturaleza y no sólo como un instrumento para dominarla (para la filosofía aristotélico-tomista, en el conocimiento se da una co-actualidad de formas. Por eso decía aquel moderno Aristóteles que fue Leonardo Polo que el olvido del ser denunciado por Heidegger como olvido de la idea de ser, era en realidad un olvido del acto de ser, y consecuencia éste de un previo olvido del acto de conocer). 
Hay también una relación armoniosa y natural entre ciencia y filosofía. La filosofía ha servido a la ciencia no sólo por el hecho histórico, meramente circunstancial, de que dio a luz, en su seno, a la ciencia física (como recordaremos en la sección tercera), sino porque presta, también aquí, una conceptualización adecuada para las ciencias, y una reflexión sobre su fundamento y sobre la fiabilidad de su método, señalando los límites naturales de la ciencia y los límites entre unas y otras ciencias. Por otra parte, la ciencia sirve de base a la filosofía -y más ha de servir todavía, pues aún hay quien filosofa como si en el mundo sólo hubiera mesas, árboles y manzanas- ofreciendo a su reflexión una imagen del mundo cada vez más adecuada: se ha ayudado a la razón natural de un microscopio para ver lo muy pequeño del mundo, de un telescopio para ver lo muy grande, y de unas gafas mágicas para ver lo invisible de sus leyes.

Y también hay una relación armoniosa, cerrando este triángulo, entre fe y ciencia, como entre una persona enamorada y las cosas todas de su persona amada, aquéllas que siquiera toca. El hombre de ciencia que alberga el amor de Dios ama la Creación porque es suya y le interesa e indaga en ella. Y está cierto de que toda verdad es su Verdad. Está cierto de que hay leyes en esa creación porque "il primo Amore" fue también la "Somma Sapienza", la inteligencia suma, como Dante nos recuerda Y está cierto también de que puede hallar esas leyes porque su propio entendimiento es imagen y semejanza del entendimiento divino. Ésta es la seguridad que llevó a J. Kepler a buscar leyes en los planetas. En la introducción a su "De Armonice Mundi", dice de las leyes naturales: "Dios quiso que las reconociéramos al crearnos según su propia imagen, de manera que pudiéramos participar en sus mismos pensamientos" (Kepler 1993). Y no es ésta una consideración bella pero teórica, sino que, como recordó Benedicto XVI en su discurso el 12 septiembre de 2008 en Les Bernardins, los monjes medievales -quienes primero cultivaron la teoría del movimiento que desembocaría en la ciencia físicatenían el estudio como parte de su regla benedictina, particular vía -"ora et labora"- por la que sus almas medievales salieron en búsqueda de la persona amada. 
Pero, desgraciadamente, no siempre han sido armoniosas las relaciones entre estos ámbitos, pues se han dado intromisiones entre ellos que intentaré describir en la siguiente sección ${ }^{4}$.

\section{Casos de invasión entre estos ámbitos}

Creo que entre razón y fe se han dado casos en que una de ellas ha sobrepasado sus propios límites, invadiendo el campo de la otra, pero intentaré tratar esto de modo somero, pues mi interés primordial en este artículo es la relación de la ciencia con la razón y con la fe.

A mi entender, la razón ha invadido el campo de la fe siempre que ha intentado eliminar de ésta el elemento sobrenatural y reducirla a un mero mensaje filosófico; por supuesto, mensaje de la filosofía del propio invasor, algo que ha ocurrido con el protestantismo liberal del siglo XIX (reductor, por ejemplo, de cualquier milagro), la filosofía marxista (en su intento de asimilar el cristianismo) y en su tiempo la filosofía idealista, por citar un caso en que se afirma explícitamente que la verdad de la fe

4 Quizás el final de esta sección pueda ser el momento de decir que en este artículo sobre relaciones entre ciencia, razón y fe, he tratado más de las relaciones de la razón y la fe con la ciencia, que de relaciones de razón y fe entre sí, distinguiendo entre lo que es imagen del mundo aportada por la ciencia y la que puede ser alcanzada en la reflexión filosófica o en la reflexión teológica sobre la palabra revelada. No estaba en mi intención distinguir entre estos dos últimos, y en particular el interesante tema de las verdades de fe que se hallan en el umbral de la razón, aunque algo haya aparecido de modo indirecto. Se trata de verdades de la fe cristiana que están presentes, de un modo u otro, en las demás religiones, pero que se hallan con dificultad -o sólo de un modo vago- en la especulación filosófica pagana: que el Dios de la filosofía -Causa Primera, Acto Puro, Ser Necesario- sea de hecho personal, providente y remunerador (lo que entraría en su atributo de justicia); que el alma o principio de unidad y vida en el hombre, forma sustancial -y realidad pues inmaterial- en Aristóteles sea de hecho alma espiritual -más que inmaterial-, es decir alma que puede subsistir independiente de la materia y que de hecho subsiste, alma inmortal. Las reconocemos como verdades de razón al verlas presentes en religiones no reveladas, y entendemos que el hombre ha llegado a ellas en su razón especulativa (el alma en Santo Tomás como principio de operaciones espirituales -entendimiento y libre albedrío-) o en su razón práctica (Dios y la inmortalidad del alma en Kant como realidades conocidas en la reflexión sobre el dictado de nuestra conciencia). Pero hay cierta presencia de estas verdades ya en la filosofía griega. Platón habla de la inmortalidad del alma en el Fedón, y Aristóteles considera inmortal al entendimiento agente, aunque como noûs impersonal. 
no es sino la verdad misma de la filosofía, aunque expresada "en la representación religiosa” (Georg Hegel, en su “Introducción a la Historia de la Filosofía”). Aunque no soy teólogo, tengo la intuición de que el programa de Karl Rahner de aproximarse a los misterios de la fe cristiana mediante una profundización en el misterio del hombre tiene el peligro de que podría despojar la fe de su elemento revelado y sobrenatural, proyecto que resulta reminiscente del programa de Heidegger, perfectamente explicado en su introducción a “Ser y Tiempo”, por el que el filósofo se habría de asomar al hombre, como a unas gafas transparentes, para, a través del hombre, llegar a comprender el sentido del ser (escríbase "ser” con mayúscula, y éste aparecería como el programa de Rahner). Si esta intuición fuese correcta, nos hallaríamos ante un caso -tan influyente en la teología católica de la segunda mitad del siglo XX- de invasión metodológica de la filosofía en la teología.

Casos se han dado también en que ha sido la fe quien ha invadido el campo de la razón. Esto es lo que viene a denunciar Santo Tomás cuando enumera en la "Summa contra Gentes” (Tomás de Aquino 1967, 1. II, c. 38) una serie de pruebas con que muchos "se han empeñado en demostrar" filosóficamente que el mundo ha tenido un principio temporal, en realidad porque así lo han leído en la Biblia, pues sus razones filosóficas nunca son concluyentes (otra cuestión es si es ésta una verdad de fe, lo que tampoco parece el caso, tal como comentaré en la cuarta sección). El lector de filosofía escolástica tardía puede ampliar fácilmente este ejemplo con los suyos propios. Sin embargo, en el terreno de la razón práctica, no creo que el Magisterio espiritual de la Iglesia exceda su competencia al entrar en el terreno ético dirigiéndose a todos los hombres, no con base en la palabra revelada sino con argumentos que todo hombre puede entender. Esto es así porque el espíritu cristiano supone el espíritu humano, de modo que los mandamientos de la ley de Dios y muchas de las enseñanzas de Jesucristo no son sólo para aquel rebaño bajo un solo pastor, sino para todos los hombres. Así, por ejemplo, la enseñanza de la Iglesia sobre límites éticos en ámbitos particulares de la investigación científica, no es una injerencia ilegal en la ciencia sino un pronunciamiento, que no extralimita su com- 
petencia, en material de moral. Y el hecho de que haya límites éticos de la investigación está claro, a menos que demos por válida cualquier manipulación con fines científicos, por ejemplo la inoculación de enfermedades graves a poblaciones ignorantes para poner a prueba un nuevo fármaco (se ha hecho a poblaciones de Centroamérica), o las horribles amputaciones llevadas a cabo incluso a niños en la población de cobayas humanas de que dispusieron, en torno a los campos de concentración, los investigadores nazis y japoneses.

Pero tratemos de lo que el lector más espera, los casos de invasión entre ciencia y religión, aunque creo voy a defraudarle, por un doble motivo. El primero es que, en vez de casos de invasión de la religión en la ciencia, habría que hablar de caso, pues sólo se ha dado el que el lector está pensando, lo que demuestra que más bien que de la regla, se trata de la excepción, de hecho un caso de incomprensión inicial al empezar la andadura de la ciencia de la naturaleza. Puede argüirse que además del caso Galileo, estuvieron las penas mucho más graves -condena a la hoguera- de Giordano Bruno y Miguel Servet. Pero en cuanto a Bruno, aun con todo lo que supone de profunda turbación y desorientación para el alma del creyente que quienes han recibido el mandamiento del amor hayan llegado a quemar viva a una persona por defender sus convicciones, no puede decirse que fuese condenado a la hoguera por sus opiniones científicas, sino por su panteísmo teológico (Bruno, panteísta, no busca leyes en la naturaleza porque Dios no está sometido a leyes). Y en cuanto a Servet, quemado en la hoguera por Calvino (él mismo allí presente), no lo fue por sus opiniones sobre la circulación de la sangre, sino sobre la Trinidad. Así pues no hay más condenas de la Iglesia Católica a un científico que la reclusión en su propia villa de Arcetri, y rezo diario del Salmo 50, a Galileo Galilei. Y es que la Iglesia aprendió pronto, y nunca permitió una segunda edición de este lamentable caso. Cuando en 1870 algunos obispos pidieron en el Concilio Vaticano I que se condenase el evolucionismo -otros, por supuesto, pedían lo contrario- bastó un argumento para que se evitara tal condena (la Iglesia tan sólo pide a los cristianos que no vean el alma espiritual del hombre como surgida por evolución de la materia). Al parecer, el argumento que 
convenció provino de un obispo que empleó sólo dos palabras: "Mementote Galilei” (¡Acordaos de Galileo!).

Y en cuanto al caso Galileo, del que he tratado en otro lugar extensamente (I. Sols 2012), ¿qué decir en dos pinceladas? En el aspecto científico, es cierto que no estaba demostrado que la tierra se moviese a lo largo del año pues habían buscado sin éxito paralajes (distintos ángulos desde los que se ha de ver el universo desde la tierra según las distintas épocas del año. De hecho las paralajes tardaron dos siglos en aparecer, cuando Bradley ya había demostrado el movimiento de la tierra al encontrar, en 1725, la aberración de la luz: al moverse la tierra, la luz de las estrellas debe llegarnos con cierto ángulo -distinto según las épocas del año-como una gota de lluvia que cae en vertical para un observador en reposo, cae con un cierto ángulo para un observador en movimiento). Por lo tanto, en rigor, el movimiento de la tierra sólo podía ser mantenido y enseñado como hipótesis, y esto exigía la Iglesia en tanto que fuese científicamente demostrado (aunque hipótesis no significaba entonces tesis probable sino instrumento o ficción para el cálculo matemático (I. Sols 2012)). Pero lo que interesa aquí es lo que el caso tiene de relación entre fe y ciencia, y en ese aspecto era Galileo quien tenía razón: se trataba de una invasión de la religión en el ámbito de la ciencia, algo totalmente indebido pues no está la Biblia, verdad revelada, para enseñarnos doctrina alguna natural, sino para enseñarnos a los hombres el camino de la salvación.

El segundo motivo por el que en esta interfaz ciencia-fe vaya a quedar el lector defraudado es que poco diré de casos de invasión de la ciencia en el terreno de la fe. Seguro que al lector tiene presente casos en que algún científico, en virtud de la ciencia, niega la existencia de Dios o cualquier traza de espíritu, como en aquella época en que Laplace negaba, en nombre de la ciencia, la libertad humana, dejando pues sin base la responsabilidad moral del hombre, elemento fundamental de las religiones. De estos casos trataré, ciertamente, pero no quiero hacerlo aquí, puesto que eso sería conceder que se trata de cuestiones religiosas, cuando en realidad son filosóficas (aunque una respuesta negativa a cualquiera de ellas, cerraría la filosofía a la posibilidad de la religión). Pero quienes estas cuestiones susci- 
tan en nombre de la ciencia tienen de ordinario una mentalidad positivista según la cual las cuestiones filosóficas no tienen sentido, por lo que es difícil que admitan que se trata de tomas de postura en materia filosófica. En resumen, convendrá tratar más tarde de este tema, al hablar de casos de invasiones entre el ámbito científico y el ámbito filosófico. Y entonces no lo trataré como caso de invasión de la ciencia en la filosofía, porque nada de esto dice la ciencia, sino invasión de la filosofía en la ciencia, pues se trata de opiniones filosóficas personales -aunque no reconocidas- profesadas con tal celo que se fuerza a la ciencia a decir lo que la ciencia no dice. (Y en el caso de Laplace, la ciencia dice más bien lo contrario, como demostraría más tarde la teoría del caos, algo que recordaremos en la sección cuarta).

Llegamos pues a la interfaz ciencia-filosofía. Hay profundidad en el modo en que el método científico ha invadido la reflexión filosófica, no por asalto de la ciencia, sino por el intento de emular el método científico en el pensamiento filosófico. En una teoría científica los conceptos son definidos por la propia teoría, en esa definición del objeto bajo estudio que son los axiomas de la teoría y la definición específica de cada concepto en ella introducido. Se trabaja pues con ideas claras y distintas, pues no son más que la definición que de ellas ha dado la teoría misma, y eso comporta una claridad en el razonamiento científico que ha sido exigida luego a las ideas filosóficas. Ésa es la razón por la que la noción de sustancia ha sido expulsada de la filosofía. Locke fue el primero en decir que mejor se pasaría la filosofía sin esta noción (aunque él no pudo prescindir de ella), y la razón aducida era que no tenemos de las sustancias una idea clara y distinta, sino oscura y confusa (Locke 2005). Por razón análoga desaparece la noción de causa, muy debilitada por la previa desaparición de la sustancia en la obra de Berkeley (pues, por usar el ejemplo de Hume (Hume 1981), no son los accidentes que percibimos - un color y un brillo- lo que causa la carbonización de un papel sino el fuego, algo que tiene ese color y ese brillo). La filosofía de Kant es entonces un intento de salvar como apriorismo del entendimiento la causalidad y otras realidades -espacio, tiempo, Dios, Mundo, Yo-perdidas en Hume, pues entiende que sin estas nociones 
no es posible la matemática, ni la física, ni es posible poner en orden las propias ideas: sencillamente, no es posible el conocimiento. He ilustrado mi afirmación con estas dos breves pinceladas, pero es posible seguir, autor por autor, la filosofía moderna -siglos XVII y XVIII- encontrando en todos este intento de constituir la filosofía con la claridad de la ciencia. Por eso hubo racionalismo y hubo empirismo, correspondiendo al método empírico y racional en la construcción de la base experimental y en la fase teórico-deductiva de la ciencia. Es común al racionalismo y al empirismo modernos esa exigencia de ideas claras y distintas en filosofía. Ya antes René Descartes había hablado de su propio sistema como una philosophie mathematique, y Spinoza llamó a su obra principal "Ethica ordine geometrico demonstrata”, un libro todo él dispuesto según el sistema de definiciones, postulados, proposiciones y corolarios de los Elementos de Euclides, lo que deja bien clara su intención (Spinoza 2005).

Sin embargo, el método de la teoría científica no servirá nunca para la especulación filosófica. Una teoría científica estudia el objeto que ha construido al poner sus postulados y definir ese objeto, pero esto no es posible en filosofía, pues no se trata en ella de reflexionar sobre nuestras propias definiciones sino sobre los seres, no tal como los definimos sino tal como son. Este gesto emulador del método científico queda pues abocado a un encerramiento en nuestras propias ideas, en un mundo que es puro pensamiento -subjetivismo- y así, perdido el ser, se llega al idealismo, donde todo es idea.

Llegamos finalmente a la invasión contraria, a los casos en que ideas filosóficas se han entrometido en la ciencia. Esto ha ocurrido a veces de modo inadvertido, como en la ocasión en que el prejuicio panteísta de Einstein -y consiguiente creencia en la eternidad del universo- le llevó a introducir en su inicial ecuación de campo, $\mathrm{G}=8 \pi \mathrm{T}$, postulado del que se deduce toda la relatividad general (y del que hablaremos en la sección 3), una forzada constante cosmológica, $\mathrm{G}=8 \pi \mathrm{T}+\lambda$, para permitir como solución un universo eterno, Einstein consideró esta constante cosmológica l como la mayor metedura de pata de su vida ("the biggest blunder of my life"), pues le impidió a su teoría predecir la expansión del universo, que hubo 
de ser primero observada experimentalmente. Y se ha dado de modo claramente advertido cuando, por ejemplo, se prohibió en Rusia la Mecánica Cuántica porque se consideraba doctrina burguesa y contraria al materialismo dialéctico de la filosofía marxista. (Cuando, años más tarde, se permitió a sus científicos estudiar la Mecánica Cuántica, Landau llegó a decir que para entonces “ya habían sacado a bailar a las chicas más guapas”, tan rápidamente se había desarrollado lo esencial de esta mecánica antes de que ellos llegaran).

Es difícil determinar si es advertida o inadvertida esa invasión de campos que se produce con frecuencia en la actualidad, cuando un ambiente positivista que descarta la filosofía como conocimiento válido y que todo lo cifra en la ciencia, lleva a preguntar a los científicos cuestiones que no son científicas sino filosóficas, a las que la ciencia no puede responder. En muchas ocasiones, el científico es honesto y responde como hombre, y autorizado como todo hombre a reflexionar y opinar sobre esos temas, pero dejando claro que no se trata de la respuesta de la ciencia, pues su ciencia no trata de eso. En otras ocasiones no se hace esta salvedad, y aun a veces casi se da a entender que eso dice la ciencia, o que una opinión distinta sería incompatible con ella. Y en otras ocasiones, sin siquiera ser preguntado, el científico escribe libros de divulgación de la ciencia que son libros de filosofía materialista pero presentada ésta como conclusión científica, o dejando esa impresión, por el hecho de ir entremezclada de a veces muy amena divulgación científica.

Un ejemplo paradigmático lo tenemos en la divulgación de Stephen Hawking que recordaré en detalle en la sección cuarta (Hawking 1988; 1998). Al hablar de la posibilidad de llegar a una descripción del universo sin singularidad inicial, se pregunta “¿qué papel jugará ya entonces el Creador?” La respuesta cabal debe ser: ninguno. Como tampoco lo juega ahora ni lo ha de jugar nunca en la física. No creemos en Dios por razón física alguna, ni porque el universo, o su inicio, sea de un modo $u$ otro, sino porque hay ser en vez de nada. Dios es la respuesta a una pregunta filosófica, no a una pregunta científica. Ni la idea de Dios, ni la idea de ateísmo o agnosticismo son ideas de la matemática, ni de la física, ni de la química 
ni de la biología. Dicho de modo más claro: ningún teorema matemático, ninguna teoría física, ningún experimento químico, ninguna explicación biológica podrá jamás demostrar que Dios existe. Como tampoco podrá descartar su existencia. Dios, sencillamente, no aparece en la ciencia, como no aparecen las pequeñas angulas en una red de amplia malla lanzada al mar para pescar grandes atunes (el ejemplo, en otro contexto, es de Popper), no porque no haya angulas en el mar -que no lo sabemos- sino porque esa red no sirve para atraparlas. Dios no aparece en la ciencia no porque no haya Dios -algo que nunca sabrá la física- sino porque su método experimental no está diseñado para el acceso del hombre a la divinidad. Lo mismo podríamos decir de otras realidades, pero bástenos ésta, la de mayor importancia, como botón de muestra.

Esto no significa que no sea deseable algo que de hecho considero urgente necesidad: que la reflexión filosófica actual arranque del mundo tal como hoy nos lo presenta la ciencia, pero dejando siempre claro que se está ya en filosofía y siempre que se arranque desde ciencia real, ciencia establecida, no desde ciencia conjetural y mucho menos ciencia prometida, desde la que todo puede ser probado.

Sin embargo, los legos en materia científica tienen dificultad para saber si se está en ciencia o se está en especulación filosófica, y si se está hablando de ciencia establecida, de ciencia meramente conjetural (algo serio y habitual en la actividad científica) o incluso de ciencia prometida (lo que ni siquiera sería serio dentro de la ciencia). A algunos les suena tan fantástico que se hable del universo en los primeros segundos como del universo en ciclos anteriores al actual, sin saber que lo primero no tiene nada de fantasioso, sino que es ciencia perfectamente establecida, y que lo segundo es, al menos hoy, ciencia prometida.

Por esta razón quisiera en la sección siguiente, esbozar la visión del mundo que nos ofrece la ciencia actualmente establecida -para que quede bien distinguida de la ciencia prometida- y desde la cual sería deseable una reflexión filosófica. Y demos pues por concluida esta sección sobre invasiones metodológicas entre uno y otro campo con este consejo de la sabiduría popular: "Cada uno en su casa y Dios en la de todos". 


\section{Ciencia actualmente establecida}

\subsection{Ciencia establecida sobre la materia}

Si se nos pidiera describir la historia de la humanidad en una sección de cinco páginas, probablemente cada continente o civilización se llevaría una, y la historia de España quedaría reducida a un breve párrafo que consignara que fue tomada por musulmanes y retomada por cristianos de modo que aquí se produjo el relevo de culturas y que luego los españoles descubrieron y dieron su cultura a América, llegando a dominar el mundo por un siglo. Con esa forzosa concisión, y pensando sobre todo en estudiosos de humanidades, hablaré en esta sección del desarrollo de nuestra ciencia de la naturaleza y de la imagen del mundo que actualmente nos ofrece. Y ello con dos objetivos: distinguir, por una parte, lo que son datos de la ciencia establecida de lo que es ciencia conjetural, y, aún más, de lo que es ciencia prometida; y por otra, señalar los propios límites que la ciencia ha encontrado (ya ha aparecido uno -los teoremas de Gödel en matemáticas-y dos más aparecerán ahora, en física cuántica y en cosmología, aunque este último no es un límite absoluto sino sólo de la ciencia actual).

Todo investigador sabe lo importantes que son las buenas preguntas, y éstas las puso Aristóteles en su séptimo libro de la física (Aristóteles 1995) al preguntarse por la velocidad alcanzada tanto en el movimiento "natural" (caída de graves) como en el movimiento forzado o "violento" (cuando actúa una fuerza). La física se gestó, a lo largo de veinte siglos, en los comentarios de este libro. Fue iniciada como teoría del ímpetu, en Alejandría, hacia el año 530, por un cristiano nestoriano, Juan de Filopón, quien fue el primero en decir que los astros son de la misma materia que nuestra tierra, abandonando pues la distinción entre mundo supralunar y sublunar. Esto significa que su materia obedece a las mismas leyes, y por tanto comprenderemos el movimiento de los astros cuando comprendamos aquí abajo el movimiento. Llegó a afirmar que los graves caen aproximadamente al mismo tiempo independientemente de su peso. $Y$ en cuanto al movimiento forzado, afirmó que un cuerpo aún permanece en movimiento, al cesar de ejercerse sobre él una fuerza, debido a su ímpetu o inercia, 
especie de "virtus impresa" en él por la fuerza que lo puso en movimiento (Boyer 1999). El dominico segoviano Domingo de Soto, primero, y Galileo Galilei, después, dijeron que la caída de graves es a causa de un movimiento uniformemente acelerado, y en cuanto al movimiento forzado dijeron que no sólo se da una resistencia del medio al movimiento sino que existe una resistencia interna al movimiento, luego llamada masa, resistencia pues del propio móvil (Camacho and Sols 1994; 1995). Descartes dijo que el producto de esa masa por la velocidad -el impulso o cantidad de movimiento- es la cantidad conservada en ausencia de fuerzas, y Newton dio luz a la física, tras su gestación de siglos como teoría del ímpetu o theoria motus, al tomar como postulado de su teoría deductiva que la variación (derivada temporal) de esta cantidad de movimiento por aplicación de una fuerza iguala a la fuerza aplicada.

Como es sabido, la física newtoniana permitió un dominio de la naturaleza en los dos siglos siguientes que hizo posible nuestra civilización tecnológica. Hay que añadir la termodinámica, pero pronto Boltzmann demostró que sus leyes se deducen, por estadística de grandes números, de las leyes newtonianas que han de cumplir las partículas que componen la materia -la temperatura, por ejemplo no es sino la energía cinética de las partículas- de modo que nos encontrábamos ante una sola mecánica para explicar una sola naturaleza. La ruptura de este idilio, hasta con actitud de soberbia en algunos científicos antes del siglo XX, había de venir de la recién nacida teoría electromagnética.

A principio del siglo XIX, Alessandro Volta había inventado la pila que permite producir y mantener corrientes y, por tanto, investigar con ellas, añadiéndose entonces a la ley electrostática de Coulomb sobre atracción y repulsión eléctrica, las leyes experimentales sobre la corriente eléctrica de Biot-Savart, Joule y Ampère. Faraday llegaría a formular una teoría electromagnética desde principios no matematizados, lo que permitió a James Clerk Maxwell deducir el electromagnetismo desde unas pocas leyes matemáticas bien precisas, tomadas como postulados de esta teoría científica. Las ecuaciones de Maxwell predecían la existencia de ondas electromagnéticas propagándose en el vacío a la velocidad de la luz (lo que 
sirvió para comprender que la luz no es sino una onda electromagnética en las frecuencias visibles). Estas ondas fueron producidas por Herz mediante osciladores, dando lugar así a las comunicaciones sin cable. La situación era, como se ha dicho, de idilio, salvo que aparecía en las ecuaciones de Maxwell no sólo la constante $\pi$ sino también el valor $c$ de la velocidad de la luz. Por tanto la velocidad de la luz tenía que mantenerse constante o independiente de la velocidad del propio observador, si se quería que, como es natural en física, las leyes del electromagnetismo fuesen independientes de la velocidad uniforme del observador (en un sistema de referencia inercial). Michelson y Morley miden en 1887 la velocidad de la luz en el sentido en que la tierra avanza, a unos treinta kilómetros por segundo, tras de un rayo de luz lanzado al espacio desde ella, y en el sentido en que la tierra retrocede también a esa velocidad, respecto de la luz emitida. En vez de obtener $30+30=60$ kilómetros por segundo de diferencia, obtienen exactamente el mismo valor en ambas mediciones, lo que sugiere que la velocidad de la luz es independiente de la velocidad de quien la mide. Esta constancia de la velocidad la luz en todos los sistemas inerciales es tomada por Albert Einstein como postulado del que deducir su teoría de relatividad especial, en la cual las velocidades relativas no se calculan por simple resta o suma según el caso, como en mecánica clásica, sino que aparece un término corrector. Además, la masa, la longitud, y el tiempo no son absolutos sino relativos a la velocidad $v$ del observador, con un análogo factor corrector que depende del cuadrado de $v / c$. Como las velocidades de los observadores ordinarios han sido hasta ahora muy pequeñas comparada con la velocidad de la luz, este cociente corrector $v / c$ era prácticamente cero, recuperándose "como límite clásico" la física newtoniana, es decir, como la teoría que queda cuando se toma $v / c$ igual a cero. Para la formulación matemática de la relatividad especial es imprescindible considerar el tiempo como una cuarta dimensión, y no hablar ya de espacio y de tiempo por separado, sino de espacio-tiempo.

Más tarde, Albert Einstein se da cuenta de que una persona que cae libremente cargado con una gruesa mochila no experimenta el peso de la mochila ni su propio peso, quedando su gravedad cancelada por la acele- 
ración con la que cae, por lo que sospecha que gravedad y aceleración del observador -aceleración del sistema de referencia- son equivalentes, de modo que proyecta una geometrización de la fuerza de la gravedad: sólo hay una ley, y es que todo cuerpo sigue su propia geodésica, siendo la aceleración con la que un cuerpo se acerca a otro simplemente la aceleración con que, debido a la curvatura del espacio-tiempo, sus dos geodésicas, a medida que avanza el tiempo, se acercan una a otra, aceleración a la que llamamos fuerza de gravedad entre los dos cuerpos. La gravitación del sol consiste en que produce una profunda deformación en el espacio-tiempo que nosotros no vemos, porque sucede en cuatro dimensiones, y de ellas sólo vemos tres, no vemos el tiempo ${ }^{5}$. De este modo Einstein reduce la gravedad a curvatura en la superficie tetradimensional espacio-tiempo, la física es reducida a pura geometría, algo que condensa en la "ecuación de campo" como postulado del que derivar su relatividad general: $G=8 \pi \mathrm{T}$. Esto significa que el "tensor de Einstein" o matriz simétrica G, conjunto de datos que codifican parte de la curvatura del espacio-tiempo, es proporcional al tensor T, que codifica la masa o energía, la cantidad de movimiento, y la presión ejercida en cada dirección; en una palabra, la materia (¡Geometría $=8 \pi$ Física!).

La ecuación de campo predice que el universo está en expansión o en contracción, por lo que fue alterada por el propio Einstein, hasta que, a finales de los años veinte, el sacerdote astrónomo belga Lemaître, primero, y después, e independientemente, Hubble ${ }^{6}$, observaron que el universo está en expansión, con velocidad perfectamente calculable (puesto que el color

5 Intentaré una explicación para profanos: la situación sería análoga a quien no ve un hoyo porque tiene sólo un ojo y ha perdido la tercera dimensión que da el relieve, pero ve el efecto de la curvatura del hoyo en la desviación de las geodésicas: una bola lanzada a él, siguiendo siempre su geodésica, ve desviada su trayectoria. De este modo un cuerpo que pasa cerca del sistema solar, siguiendo siempre su geodésica ve desviada su trayectoria, y es a esto a lo que llamamos gravedad solar.

6 Desde 1984 se sabía que antes del celebrado artículo de Hubble de 1929, un artículo de Lemaître en 1927 escrito en francés en una revista belga de escasa difusión, había dado cuenta ya del desplazamiento al rojo de las galaxias y de la expansión del universo. Cuando, luego, fue traducido al inglés en una revista de mayor difusión se suprimió la sección en que se daba a conocer ese descubrimiento. En el número de Nature del 10 de noviembre de 2012, Mario Livio ha demostrado que fue el propio Lemaître quien suprimió esa sección, excusándose ante la revista porque esos datos eran "clearly of no actual interest" (!). 
o conjunto de rayas en el espectro de luz de los átomos de la materia de otras galaxias está ligeramente desviado hacia el color rojo, lo que denota que las demás galaxias se están alejando de la nuestra. Se alejan con mayor velocidad cuanto más lejos están ${ }^{7}$. Esto llevó a Lemaître a la hipótesis, e incluso estimación temporal, de un “átomo primitivo”, más tarde llamado "Big Bang”, es decir un principio del universo que actualmente se estima sucedió hace unos 13'76 miles de millones de años (con un error máximo de 0'11 miles de millones).

Casi al mismo tiempo de la experiencia de Michelson y Morley, otra experiencia habría de romper por otro frente la física newtoniana, considerada hasta entonces como definitiva. En 1900 Max Planck estudia la intensidad de radiación electromagnética emitida en cada frecuencia $v$ por un cuerpo negro que es calentado y sólo puede explicar el resultado obtenido si supone que la energía se emite en múltiplos de un valor fundamental $h v$ al que llama cuanto de energía ( $h=$ constante de Planck). Cinco años más tarde, Albert Einstein explica el efecto fotoeléctrico suponiendo que también la energía lumínica de frecuencia $v$ se produce en múltiplos de una energía fundamental $h v$, la energía de un fotón: la luz incidente sobre un metal induce un flujo electrónico, pero este efecto no se produce cuando la luz tiene suficiente intensidad, sino cuando tiene suficiente frecuencia, algo que nadie sabía explicar. Al suponer Einstein que la luz de frecuencia $v$ viene en cuantos o fotones de energía $h v$, cada uno de ellos es capaz de "arrancar" un electrón externo de aquel metal cuando la frecuencia $v$ es suficientemente alta, quedando pues explicado el efecto.

Más tarde Bohr aplica la teoría cuántica para explicar el modelo atómico de Sommerfeld: Supone que los electrones sólo pueden orbitar con radios que corresponden a un nivel energético múltiplo de un valor fundamental (número cuántico energético $n$ ). Para cada radio de Bohr, están también cuantizadas las posibles excentricidades de las órbitas elípticas (número cuántico orbital $l$ ), y para cada excentricidad, las posibles órbitas

7 Imaginemos que somos un punto en un globo con muchos puntos. Al hincharlo, se alejan más lentamente los puntos cercanos que los lejanos. Se dedujo entonces que el universo está en expansión. 
tienen orientaciones espaciales también cuantizadas (número cuántico magnético $\mathrm{m}$ ), y en cada órbita hay a lo sumo dos electrones correspondiendo a dos valores opuestos de su spin (número cuántico de spin $s$ ). De aquí se deducía enseguida que el número de electrones posibles con número energético $n$ era el doble del cuadrado de $n$. Para $n=1,2,3, \ldots$ se obtienen $2,8,18, \ldots$ electrones en cada órbita, y así el número atómico de un elemento (número de protones en el núcleo y por tanto número de electrones orbitando en torno a él) determina el número de electrones que tenga la última órbita y, por tanto, las propiedades químicas de cada elemento, ya que primero se rellenan los niveles energéticos más bajos. Quedaba así explicado que las propiedades químicas de los elementos dependían de su lugar en la tabla periódica, al ordenarlos por su número atómico, como ya había descubierto el químico ruso Mendeleev.

En 1924 Louis de Broglie lee una tesis doctoral de página y media titulada "Recherches sur la théorie des quanta", por la que recibe el Premio Nobel: si suponemos que un electrón lleva asociada una onda, para que no se destruya a sí mismo por autointerferencia, al dar una vuelta, es necesario que el perímetro recorrido sea múltiplo entero de esa longitud de onda. ¡Los radios que entonces resultan son exactamente los radios supuestos por Bohr como los únicos posibles! Por primera vez uno de los números cuánticos "supuestos" para explicar un fenómeno ha sido deducido. Se busca entonces una mecánica derivada de unos postulados, en la que todos los "números cuánticos" que habían aparecido en la teoría "cuántica" como supuestos, sean de hecho deducidos. Schrödinger, por una parte y Heisenberg y Dirac, por otra, habían conseguido desarrollar, ya para 1927, esa “mecánica cuántica”.

En ella, una partícula viene descrita por una "función de onda" que asigna a cada lugar (y estado de spin) la amplitud de probabilidad de encontrarla en ese lugar (con ese estado de spin) si se hace una observación conducente a ello. Y el postulado del que derivan su mecánica consiste en que la evolución temporal de esa función de onda viene dada por cierta ecuación, típica de las ondas, de modo que Erwin Schrödinger pudo inspirarse para ello en su trabajo previo en óptica ondulatoria (si se tiene en 
cuenta el spin, tendríamos la ecuación de Dirac). La mecánica cuántica ha puesto un segundo límite al conocimiento científico: esta onda asigna a cada punto la amplitud de probabilidad (o más bien densidad de probabilidad) de que la partícula aparezca en ese punto si se hace una observación; pero sabemos que no existe ninguna causa física que determine el lugar en que la partícula aparezca cuando se haga la observación, de entre todos los lugares probables. De hecho, no sólo la observación de la posición es aleatoria intrínsecamente -y no porque nuestra ignorancia nos obligue a trabajar con probabilidades-, sino que así sucede con la observación de cualquier magnitud física. El hecho de que esta aleatoriedad sea intrínseca, o que sea sólo fruto de nuestra ignorancia de la posición antes de hacer el experimento, fue objeto de debate hasta los años setenta en que Alain Aspect violó experimentalmente las desigualdades de Bell, dejando zanjado el debate: la aleatoriedad cuántica es intrínseca. Quienes después de ello aún siguen negando este límite de la física son científicos que en este aspecto están fuera de la corriente principal, lo que quizá se deba a prejuicios filosóficos, un nuevo caso de invasión de la filosofía en la ciencia experimental.

La teoría cuántica de campos, en el llamado modelo estándar -ampliación natural del modelo electrodébil- ha unificado la fuerza electromagnética y la fuerza débil que cambia el estado de isospín de las partículas, o más popularmente la fuerza responsable de los fenómenos radioactivos, y las ha colocado junto con la fuerza fuerte, que mantiene unidos los integrantes (quarks) de los protones -que por ser de la misma carga eléctrica se deberían repeler- en un núcleo atómico. Como se sabe, la predicción, en los años sesenta, del modelo electrodébil era una corriente neutra que apareció en el año 1984 y el bosón de Higgs que ha aparecido recientemente. Pero todavía no se ha conseguido unificar este modelo con la fuerza gravitatoria: mecánica cuántica y relatividad general se mantienen como dos teorías separadas explicando una misma naturaleza, lo que es de momento tolerable porque la fuerza gravitatoria es debilísima comparada con las demás (dos bolas metálicas cargadas con igual carga eléctrica se repelen, a pesar de la comparativamente debilísima y despreciable atracción gravi- 
tatoria entre ellas). Pero veremos enseguida que esta separación ya no es tolerable cuando pretendamos estudiar los inicios del universo, antes de diez elevado a menos cuarenta y tres segundos, pues entonces estas fuerzas deberían estar unificadas en una sola.

Aparece así otro límite, pero ya no intrínseco sino límite de la física actual, mientras no se consiga la teoría unificada. Conocemos perfectamente la física de los primeros instantes del universo (y su predicción, una radiación de fondo como la del cuerpo negro a 2'7 grados Kelvin, se ha encontrado). En efecto, como conocemos la velocidad de expansión del universo sabemos su escala en cada época, y por tanto la frecuencia, es decir la energía -o si se quiere temperatura- que tenían los fotones en esa época (hasta que los fotones se desacoplaron con la materia dando lugar a la radiación de fondo). Conocemos por tanto la materia que había en cada una de esas épocas: las únicas partículas que pueden producirse -mediante pares partícula antipartícula-y desaparecer por interacción de fotones de esa frecuencia (o temperatura). Conocemos por tanto las reacciones que había en el universo: las únicas que puede haber entre esas partículas. Sabemos pues del universo en esas eras en que los cosmólogos dividen los primeros instantes del universo mucho mejor que sabemos de él en la era actual, pero nada sabemos anterior a diez elevado a menos cuarenta y tres segundos, pues entonces eran tan pequeñas las distancias que la fuerza gravitatoria entre las partículas materiales era comparable a las demás fuerzas, sin que dispongamos de una física unificada que nos permita decir nada de ellas conjuntamente. Dicho técnicamente, todas las fuerzas estaban, a tan alta temperatura, realmente unificadas en una sola fuerza que aún no hemos encontrado. Por tanto, nada que se diga en ciencia actual o en libros de divulgación actuales en relación con lo que ocurrió en el universo antes de diez elevado a menos cuarenta y tres segundos -si hubo un universo anterior, o muchos universos formando ciclos de Big Bangs y Big Crunchs- es ciencia establecida, sino pura especulación. Y está bien especular, mientras el científico deje claro al lego que no está hablando en ese momento desde la ciencia sino desde el divertimento, algo a lo que todo el mundo tiene derecho. 
Quizá convenga, para lo que sigue, una descripción más detallada de este escenario y del modo en que ha llegado a conocerse. Cuando el escenario se abre para nosotros (en el estado actual de la ciencia), el universo tiene esa muy breve edad de diez elevado a menos cuarenta y tres segundos. En él encontramos radiación ${ }^{8}$ y materia-antimateria, relacionados ambos por dos interacciones opuestas y en equilibrio: dos fotones con suficiente energía (es decir, frecuencia) interaccionan y producen un par partícula-antipartícula; una partícula interacciona con una antipartícula suya, aniquilándose las dos y dando lugar a fotones (la integral de Feynman calcula en cada caso la probabilidad con que cada una de estas reacciones ocurre). Pero al dilatarse el universo, los fotones ya no tienen suficiente energía para la interacción de creación y sólo se produce la de aniquilación, de modo que la materia se cancela con la antimateria por mutua aniquilación no compensada por otra reacción de creación (la energía $h v$ de los fotones ha de superar, para la reacción de creación de un par partícula-antipartícula, el equivalente energético de sus masas, según la famosa fórmula de Einstein). Había entonces más electrones que positrones (antipartícula del electrón) y por tanto son los electrones los que sobreviven a esa cancelación que se produce entre el segundo cuatro y el segundo trece, como habían sobrevivido antes protones, neutrones, y neutrinos. Estos cuatro -neutrinos, electrones, protones, neutrones- forman pues la actual materia del universo. Cuando el universo se dilate más -se enfríe más-, en torno a los tres primeros minutos, los fotones no serán capaces de impedir la formación de núcleos de deuterio (protón y neutrón), helio 3 (dos protones y un neutrón), helio 4 (dos protones y dos neutrones), litio 7 (tres protones y cuatro neutrones); es la etapa de la"nucleosíntesis". Llega un momento, entre los ciento cincuenta mil y cuatrocientos mil años de edad del universo en que los fotones ni siquiera son capaces de impe-

8 En esta sección de muy abreviada divulgación sólo hablaré de fotones como partículas de la radiación, omitiendo los bosones de la interacción débil y de la interacción fuerte, pues eso me obligaría a hablar del modelo electrodébil que tuvo importancia en época muy primitiva, que aquí no llego a describir. Tampoco hablaré de la hipótesis inflacionaria, también de época anterior a la aquí considerada. 
dir que los electrones - cargados negativamente- orbiten entorno a esos núcleos, cargados positivamente, es decir, no pueden impedir ya que se formen átomos. La carga neutra de los átomos recién formados supone una cancelación, por compensación en cada átomo, de la carga eléctrica, positiva y negativa, de las partículas del universo en esos primeros cientos de miles de años. Empieza a sentirse entonces la atracción gravitatoria (hasta entonces despreciable, en comparación con la fuerza eléctrica), y así el polvo de átomos empieza a concentrarse por acción de la gravedad en torno a zonas de mayor densidad, dando lugar a las galaxias primero, y al seguir concentrándose el polvo de una galaxia, dando lugar a sus estrellas. En una estrella, la gravedad llega a situar tan cerca unos átomos de otros que se produce entre ellos una reacción de fusión de sus núcleos (fuerza expansiva de explosión en equilibrio con la fuerza contractiva de la gravedad): dos átomos de deuterio funden sus núcleos (protón y neutrón) dando lugar a un átomo de helio 3, cuyo núcleo son dos protones y un neutrón, habiéndose convertido la masa del neutrón sobrante en energía. Ésta es la radiación electromagnética que nos llega del sol (calor, luz, partículas gamma), como también nos llegan esos núcleos de helio (partículas alfa) y electrones sueltos (partículas beta).

Cuando una estrella ha quemado ya, en esta reacción de fusión, todo su hidrógeno, quema entonces el helio en reacciones de fusión sucesivas que producen núcleos cada vez más pesados -con mayor número de protones y neutrones que el hidrógeno, el helio y el litio-, hasta que resulta imposible una ulterior concentración porque lo impide el principio de exclusión de Pauli; la pura matemática (si tenemos en cuenta las posibles representaciones del grupo de Lie compacto $\mathrm{SU}(2)$ ) nos dice que los átomos resultan ya incompresibles. La muerte de la estrella puede tener lugar como una estrella de neutrones, cuya ulterior concentración está detenida por otro principio de exclusión. Si la masa de la estrella no supera, en relación con su volumen, cierto límite -el límite de Chandrasekhar- muere como enana blanca.

Pero si, por lo contrario, la estrella supera el límite de Chandrasekhar, nada podrá contener ya su concentración en un punto hasta formarse un agujero negro o singularidad en el espacio-tiempo, a menos que la estrella 
evite antes esta trágica muerte estallando como supernova, o simplemente liberando al espacio materia de sus zonas más externas. Se dispersa así en todo el espacio material del núcleo de la estrella, es decir, núcleos de átomos pesados, que al volverse a juntar por efecto de su gravedad para formar una estrella de segunda generación, como es nuestro sol, y sistemas como el solar, darán lugar a oxígeno (que con el hidrógeno formará moléculas de ¡agua!), y también carbono, nitrógeno, fósforo... Los componentes básicos de la vida. Tenemos en definitiva en el sistema solar no sólo los materiales de la vida y el agua donde puedan producirse las primeras reacciones de la vida, sino también el calor necesario para ellas, que llega del sol por su reacción de fusión -fuerza expansiva en equilibrio con la fuerza contractiva por su propia gravitación-, hasta que su combustible se agote.

\subsection{Ciencia establecida sobre la vida}

Especialmente necesaria para la vida es el agua, molécula formada por dos átomos de hidrógeno y uno de oxígeno. El número atómico -número de protones en el núcleo- de un átomo de oxígeno es ocho, así que tiene dos electrones en la primera capa y seis en la exterior. Su enlace químico con los dos átomos de hidrógeno consiste en que cada uno de éstos aporta su único electrón para saturar esa capa, pues recordemos que la segunda capa de cualquier átomo queda saturada con ocho electrones. (Es menos energético el estado en que los átomos tienen saturada su última capa, y el enlace químico consiste en que un átomo cede electrones a otro para quedar ambos con su última capa saturada, obteniéndose así un estado de menor energía). La importancia del agua para la vida deriva de que, entre cero y cien grados, permanece en estado líquido, de modo que fluctúan libres los iones negativos $\mathrm{OH}$ y los iones positivos $\mathrm{H}$, por lo que muchas reacciones son posibles entre sustancias químicas sólo cuando están en disolución acuosa: la parte positiva y negativa de una molécula -átomos unidos por un enlace químico como se ha descrito- se disocia en la disolución acuosa, porque su parte negativa es atraída por iones positivos $\mathrm{H}$ y la parte positiva es atraída por iones negativos $\mathrm{OH}$. Esos iones, positivos y negativos, diso- 
ciados de las distintas moléculas en disolución, se atraen entre sí en modo que propicia nuevos enlaces entre ellos con formación de nuevas sustancias químicas. De este modo el agua propicia reacciones químicas -como por ejemplo la síntesis de las moléculas esenciales para la vida-, reacciones que de otro modo no serían posibles.

Sabemos hoy que la vida se transmite codificada en los cromosomas que hay, a pares, en los núcleos de las células de los seres vivos, largas moléculas de ácido desoxirribonucleico (ADN) enrolladas en doble hélice. Un ADN está integrado por el enlace químico entre dos polímeros (con la forma de dos largos peines que, enfrentados y unidos por ese enlace, forman una larga escalera). Los monómeros o piezas fundamentales de estos polímeros son nucleótidos formados por una base nitrogenada (adenina, timina, citosina y guanina). Ambos polímeros son complementarios entre sí: en el eslabón donde uno tiene adenina, el otro tiene timina, y viceversa; y donde uno tiene guanina, el otro tiene citosina y viceversa. Así pues una molécula de ADN es una escalera con peldaños de una de estas cuatro formas
D-Adenina - Timina-D
D-Timina-Adenina-D
D-Citosina-Guanina-D
D-Guanina-Citosina-D,

donde D (desoxirribosa) es una pentosa (molécula orgánica con cinco carbonos formando un pentágono). Todas estas moléculas que forman los peldaños elementales del ADN están formadas por unos pocos átomos de carbono, oxígeno, hidrógeno y nitrógeno. La escalera se forma por estar unidas entre sí las pentosas D de la izquierda por un fósforo, e igualmente las pentosas $\mathrm{D}$ de la derecha.

Se trata de una estructura que se duplica con facilidad (lo que ocurre en el momento de división de una célula) al deshacerse con facilidad el enlace que unía los dos polímeros que la forman (la escalera se abre en dos peines). Cada base nitrogenada de cada uno de ellos toma entonces del sustrato la base nitrogenada complementaria (la adenina toma una timina, 
etc.) con lo que se acaban formando dos nuevas cadenas de ADN idénticas a la primera, para cada una de las dos células resultantes. Esto es así tanto en el caso de la división ordinaria o mitosis como en el de la meiosis (en que las dos nuevas células serán gametos destinados a la reproducción, con la mitad de dotación cromosómica cada uno: el gameto sólo tiene cromosomas aislados, no pares de cromosomas, como es el caso de las células normales). Sin embargo, no siempre la réplica es idéntica al ADN inicial, pues se producen errores en la copia, debido a que se trata de un proceso químico que explica la mecánica cuántica y ésta concede siempre cierta probabilidad a posibles alteraciones o vías alternativas a la vía normal (esto es muy importante, pues hace a la indeterminación cuántica -intrínseca aleatoriedad- responsable de las mutaciones que darán lugar a las nuevas formas de vida). Las acumulaciones de errores en las réplicas que suceden en el crecimiento y renovación de las células a lo largo de la vida de un ser vivo son causa parcial de su envejecimiento, con disfunción final y muerte. En el caso de la meiosis, división celular en dos gametos destinados a la reproducción, se producen además, antes de la división, intercambios entre partes del ADN, lo que supone una fuente adicional de mutaciones en el ADN de los gametos.

Las moléculas de $\mathrm{ADN}$ en el núcleo de la célula son el código de la vida, pues cada triplete de nucleótidos (tres peldaños de la escalera) tiene afinidad por uno de los veinte aminoácidos -veinte moléculas de muy pocos carbonos que son los veinte ladrillos de que está hecha, fundamentalmente, la materia viva- que forman las proteínas. De este modo, unos cien o doscientos tripletes de la escalera catalizan la yuxtaposición de una secuencia de unos cien o doscientos aminoácidos tomados del sustrato, yuxtaposición por la que se produce el enlace químico entre ellos hasta formar un monómero, protómero de una proteína. Este es el modo en que se sintetizan las proteínas en los miles de ribosomas suspendidos entre las cisternas de la célula; mediante un ácido ribonucleico ARN mensajero que lleva la información de un segmento del ADN desde el núcleo hasta esos ribosomas donde se sintetiza el monómero codificado por ese segmento y al unirse éstos se forman las proteínas. 
Cada proteína adopta espontáneamente una forma geométrica determinada por la secuencia de aminoácidos que la forman (al agruparse entre sí los que son liposolubles, como se agrupan las gotas de aceite en una disolución acuosa). Esta forma espacial es la responsable de las propiedades funcionales de la proteína, como por ejemplo su actividad catalizadora al funcionar como llave -geométricamente como una llave- en cuyos pliegues se ajustan bien, por pura casualidad, diversas moléculas orgánicas. Por ejemplo, su actividad reguladora sobre el ADN: una proteína inhibe la formación de ARN mensajero para la síntesis en los ribosomas del protómero de la proteína necesaria para metabolizar un producto. Ese producto tiene afinidad -meramente geométrica- con una parte de la proteína inhibidora, por lo que su presencia induce que la proteína inhibidora interaccione con él, cesando así su acción inhibidora de la formación de la proteína necesaria para metabolizarlo, y consiguiéndose así que esa proteína se forme, para ser, pues, metabolizado. Mecanismo ciertamente ingenioso. Lo que parecía un milagro -que la presencia de un producto induzca la síntesis de la proteína que lo ha de metabolizar- ha quedado ahora explicado por las propiedades espaciales de la proteína, mera consecuencia de cuál sea la secuencia de aminoácidos que forman su protómero.

Volviendo ahora la mirada hacia la reproducción de la vida, recordemos que en el momento de la duplicación del ADN, para ser ADN de un nuevo ser vivo, se producen errores con cierta probabilidad para las vías mutantes que, a la postre, viene asignada por la Mecánica Cuántica, y por tanto de modo intrínsecamente aleatorio. Normalmente, estas mutaciones no cambiarán nada, o si cambian lo harán a peor, pero puede darse el caso de que se trate de un cambio por el que la descendencia de ese individuo tenga más oportunidad de sobrevivir que otros individuos de su misma especie, carácter que aparecerá entonces como adaptación al ambiente, como si hubiese sido una mutación "para” adaptarse. Muy conocido es el caso en que se pintó de blanco el tronco de los árboles de Londres para que ciertas mariposas de color negro, de malignas orugas, fuesen avistadas y devoradas por los pájaros. Al cabo de un tiempo esas mariposas eran blancas, es decir, que habían adaptado su color "para” hacer frente al peligro de los 
pájaros. De este modo han ido evolucionando las especies vivas, desde la primera bacteria hasta la flor y hasta la abeja que liba la flor: mutaciones al azar -azar previsto por la mecánica cuántica- seguidas de selección natural. Otro ejemplo lo tenemos en el final de las epidemias mortales: en una de las mutaciones azarosas que se producen al duplicarse la molécula de ADN del virus o bacteria causante de la epidemia, surge una variante que causa una versión menos maligna -ya no mortal- de la enfermedad. Por tanto los descendientes del virus o bacteria mutados en ese sentido tendrán más probabilidades de sobrevivir, de modo que serán éstos los que acabarán imponiéndose.

Hemos explicado el nacimiento del sol, y el de la flor y el de la abeja que la liba en la mañana soleada; explicados todos ellos desde una primera bacteria por este proceso de mutación seguida de selección natural. Pero, ¿Cómo se llegó a la primera bacteria? La simple química en la disolución acuosa puede explicar, en presencia de los átomos de hidrógeno, oxígeno, carbono y nitrógeno la formación de aminoácidos, y desde ésta, la formación de proteínas; se puede explicar la formación de nucleótidos y desde éstos las primeras moléculas de ADN. Pero llegar a explicar la formación de la primera bacteria -si bien hay hipótesis plausibles- es algo que aún escapa a la ciencia actual, y resulta muy difícil por la falta de fósiles de bacterias.

En el otro extremo de este arco comprensivo, nos encontramos con el cerebro, y ahí es mucho más lo ignorado que lo conocido. Sabemos que las neuronas están interconectadas de modo que, recibiendo una por sus neuritas las señales que otras neuronas emiten por sus dendritas, emite entonces la neurona, o deja de emitir, una señal por su dendrita -a su vez será señal de entrada para otra neurona- según que la suma de las señales recibidas sobrepase o no cierto umbral. Además, la señal emitida por una neurona puede resultar inhibidora para que otra neurona emita su propia señal. Componiendo de este modo neuronas en serie y en paralelo, se puede conseguir que implementan las funciones “y”, "o", "negación” e “implica” del cálculo proposicional (correspondiendo una señal al valor de verdad 1 , y la ausencia de señal al valor 0). Es así como se hace en los circuitos 
lógicos en los que este comportamiento de las neuronas es implementado electrónicamente y en la teoría matemática de neuronas formales -mimetizando las neuronas reales-, teoría iniciada por McCulloch y Pitts , que ha tenido una amplia aplicación en el diseño de ordenadores.

Las redes neuronales implementan cualquier algoritmo o máquina secuencial, es decir, una emisión de respuesta u output determinada en función del input que recibe y de su propio estado interno. Se ha llegado a redes neuronales que no necesitan ser programadas sino que se autoprograman, con una eficiencia bastante razonable, para hacerse capaces de responder a una determinada pregunta, a vista de muchos ejemplos de entradas y respuesta correcta a esa misma pregunta. Las neuronas del cerebro de los animales están conectadas formando redes -lo que imitan las redes de neuronas formales-, algo que supone ciertamente una ventaja evolutiva. Los animales no programan sus propias redes neuronales, pero quizá, al igual que las redes neuronales de la más reciente informática, se autoprogramen sus redes mediante cierto proceso de aprendizaje en vista de respuestas que encuentran satisfactorias.

\section{5. ¿Es la ciencia establecida problemática para la fe?}

Parece que no debería serlo, puesto que la fe nos abre a la verdad revelada por Dios en su único Hijo, y la ciencia a esa otra revelación suya que es la Creación. Sin embargo se oyen a veces voces contrarias, como aquella famosa de Laplace -en la época de la revolución francesa y posterior- quien veía razón para no creer en un Dios providente ni en la libertad humana a partir de la imagen determinista del mundo que le parecía presentar la física newtoniana (ciencia que se tomaba como definitiva), o en quienes creyeron que la ciencia física presentaba una imagen eterna del mundo. Como hemos visto en las dos secciones anteriores, ya no se mantienen en ciencia esas imágenes del mundo después que se encontró que el universo está en expansión y después que la mecánica cuántica -con todo su bagaje de indeterminismo- fue inaugurada. Incluso sabemos que la mecánica del tiempo de Laplace, la mecánica clásica, no es determinista, pero los 
matemáticos hubieron de tardar un siglo hasta darse cuenta de ello (con la teoría del caos). También ahora se alzan voces, aunque con argumentos distintos, en el sentido de contraponer la ciencia a la religión, por lo que quisiera proporcionar en esta sección -la que ha motivado este artículo y para la que han sido las anteriores mera preparación- un criterio para contestar negativamente a la pregunta que la titula. Aunque quizás al lector le vendrán a la mente autores de mayor actualidad, creo que esas voces actuales quedan bien representadas en tres autores de innegable altura científica: Alan Turing, Jacques Monod y Stephen Hawking. En efecto, creo que las objeciones a la fe que se han puesto desde la ciencia en el pasado y en la actualidad, y probablemente en el futuro, vienen a ser variaciones o análogos de las tres objeciones que aquí vamos a tratar, poniéndolas en boca de tres científicos de indudable prestigio.

Consideremos la pregunta que titula el famoso artículo de Alan Turing en 1950 (Turing 1976): “¿Pueden las máquinas pensar?”. Él considera que esta pregunta equivale a si pueden las máquinas llegar algún día a pasar con éxito el hoy llamado "test de Turing": que conociendo una persona tan sólo sus respuestas - sin ver la máquina- no pueda distinguir si proceden de otra persona o de una máquina (personalmente estimo que no es equivalente parecer persona y ser persona, como no es equivalente parecer alegre y estar alegre). Turing profetiza que eso habrá sucedido para final de siglo -pero no ha sucedido-, y afirma que cuando eso ocurra, al ser entonces las personas indistinguibles de las máquinas y ser el comportamiento de las máquinas determinista, habrá que deducir que nuestro comportamiento es en realidad determinista, en contradicción con la creencia en la libertad que está en la base de la doctrina moral de las religiones.

Otra voz viene de Jacques Monod, premio Nobel de Medicina de 1965 por sus trabajos sobre regulación enzimática. El mundo vivo que antes de Darwin habíamos entendido como preñado de finalidad, algo en que veíamos la mano de Dios, aparece ahora, en su famosa obra "El azar y la necesidad" (Monod 1970) como mero fruto del azar -mutaciones fortuitas- y de la necesidad de la lucha de los seres vivos por sobrevivir. Nos vemos ahora solos, no como objeto final de un gran plan, sino rodeados 
de seres inferiores que son, como nosotros, mero producto del azar y de la necesidad. La finalidad en el mundo y del mundo fue pues una imagen religiosa que se ha desvanecido ante la imagen de la naturaleza que nos ha presentado la ciencia. Aunque Monod ya falleció, en 1976, algún biólogo actual ha vuelto a presentar el darwinismo como visión del mundo cerrada a la transcendencia.

La tercera voz, más actual nos llega de Stephen Hawking en sus obras de divulgación “Breve historia del tiempo" (Hawking 1988; 1998) y "El gran diseño” (Hawking 2010). En la primera obra afirma que Santo Tomás puso filosóficamente un origen temporal en el mundo al llegar a Dios, con sus vías, como Causa Primera. Afirma, aunque sin cita alguna, que la Iglesia se apropió del Big-Bang (“seized on the Big-Bang”) en 1951 al proclamar oficialmente que estaba de acuerdo con la Biblia (probablemente se trata de alguna afirmación de que no están en contradicción. Paradójicamente, en este libro sobre el Big-Bang, aunque cita al autor de cada propuesta o hallazgo, olvida citar a Lemaître). Pero hay propuestas en que las cosas no discurren así. Por una parte, la propuesta de que el universo actual procede de un Big-Bang (explosión) resultado de un Big-Crunch (implosión) de un universo anterior, de modo que es pensable que el tiempo sea infinito con un universo que cíclicamente explote e implote. Expone también la propuesta de que el Big-Bang del universo actual haya procedido de una de las fluctuaciones cuánticas del vacío (estados a los que la mecánica cuántica asigna una cierta probabilidad). Reconoce que en la actual teoría del Big-Bang es necesario acudir a un Creador, al estar muy bien ajustados los parámetros iniciales (si el universo hubiese explotado con una cienmilmillonésima más de velocidad no se hubieran formado las galaxias y estrellas por haber sido comparativamente insuficiente la gravitación; y si hubiera explotado con una cienmilmillonésima menos de velocidad habría sido comparativamente excesiva la gravitación y hubiera implotado inmediatamente). Esto le hace sentirse molesto y da a conocer su propuesta de eliminar el modelo del Big-Bang haciendo una rotación de Wick, es decir pasando a tiempo imaginario. Es posible que no haya entonces singularidad inicial sino que aparezca el universo como super- 
ficie riemanniana compacta9. Según esta propuesta no hay pues un punto singular, no hay un Big-Bang. Amplía luego la propuesta en el sentido de que todos los universos posibles -superficies tetradimensionales riemannianas compactas- se den, en superposición cuántica coherente, cada una con una distinta amplitud de probabilidad (es decir, teniendo en cuenta, la suma sobre historias de la Mecánica Cuántica, pero tratándose aquí de la historia de todo el universo). Como ha comprobado en algunos casos, tendrían mayor probabilidad los universos con las características del nuestro, lo que explicaría que nuestro universo, el actualmente "observado" por esos observadores que somos nosotros, tenga las características óptimas para las que antes teníamos que recurrir a un Creador. Explicado esto, y ya sin Big-Bang, se pregunta: “What place, then, for a Creator?”. “¿Qué papel juega ya el Creador?".

El problema es que, aunque se responda ahora -ciertamente, sin excesivo esfuerzo- a las voces que ahora presentan como incompatibles ciencia y religión (como hace dos siglos aquella voz de Laplace hoy desautorizada por la ciencia), surgirán en el futuro, de década en década, otras voces similares, por lo que preferiría responder a todas ellas, actuales y futuras, de golpe, dando más bien unos criterios o principios en que inspirar cualquier contestación. Para ello quiero reseñar, en primer lugar, las posturas filosóficas que cerrarían el paso a la posibilidad de la fe; en segundo lugar, los posibles datos científicos que apoyarían esas posturas; y en tercer lugar, si esos datos se dan o no se dan en la ciencia.

Comenzando por las posturas que cierran el paso a la fe, éstas serían:

0) Escepticismo ontológico y escepticismo gnoseológico. El primero es la duda o negación de que exista una realidad externa a nosotros, más allá de nuestro puro pensamiento. El segundo es la duda o negación de que, en caso de que exista esa realidad, podamos conocer algo de ella (no digo conocerla en su totalidad, lo que ningún humano pretendería, sino “conocer

9 Por riemanniana se entiende que la coordenada tiempo se ha asimilado a las tres coordenadas espaciales, de modo que han resultado cuatro coordenadas espaciales. Por riemanniana compacta se entiende que no hay puntos singulares ni bordes, como no los hay en la superficie de una esfera, de un doughnut o de cualquier otro cuerpo liso. 
algo" con objetividad). Se trata pues de la negación de la posibilidad misma de nuestro conocer.

1) Materialismo. No hay más realidad que aquélla que podemos conocer por la experiencia sensible, o por su prolongación en la ciencia experimental. Se trata pues de negar la posibilidad misma del espíritu.

2) Determinismo. El estado de la realidad en cualquier instante determina su estado en cualquier instante futuro. Se niega pues la posibilidad de la acción libre de Dios sobre el mundo y de la acción libre del hombre sobre él.

Está claro que 1) cierra el paso a la posibilidad de la religión, religación entre criatura y Creador, entre alma y Dios, pues al negar el espíritu, niega en particular el espíritu divino y el espíritu humano, el alma.

Y está claro que 2) también cierra el paso a la religión, pues, al negar la posibilidad de acción libre humana, niega toda responsabilidad moral en el hombre -elemento esencial de la religión- al tiempo que niega la posibilidad de la Providencia divina sobre las criaturas, acción amorosa de Dios sobre el mundo conservándolo y conduciéndolo al fin para el que lo ha creado.

En cuanto a 0), postura que los no avisados creerán imposible en filosofía, pero que los avisados conocen bien, digamos que no sólo cierra el paso a la fe, sino a cualquier tipo de conocimiento, incluido el conocimiento científico, que quedaría en mera instrumentalización de la naturaleza, pero no verdadero saber. Con todo, hay una versión débil de 0 ) que podríamos llamar 0’) y sería el positivismo, o negación de la validez de cualquier conocimiento que no sea científico (pero ya argüí contra esto cuando puse el ejemplo de que sabemos, aunque no por ciencia experimental alguna, que el Quijote no fue escrito con un bombo de lotería. Por otra parte, el positivismo puede ser también contestado con el mismo argumento con que contestaremos el materialismo de 1): el método de la ciencia -el único admitido por los positivistas- nunca podrá demostrar que no hay conocimiento más allá del alcanzable por ese mismo método).

Habrá podido extrañar que no haya incluido entre estas posturas filosóficas aquélla que atribuyera al mundo tiempo infinito, sin principio ni 
fin. Pero algo así no podrá nunca afirmarlo ni negarlo la filosofía, pues la eternidad filosófica no consiste en ausencia de inicio o fin temporal, sino en la ausencia misma de tiempo (en este sentido se habla en filosofía de la eternidad de Dios). Ya hemos recordado que Santo Tomás refuta en la "Summa contra Gentes" (Tomas de Aquino 1967, l. II, c. 28) todos los "argumentos con los que algunos se empeñan en demostrar que el mundo no es eterno".

No es nuestra intención discutir ahora esas tres opiniones filosóficas, sino reseñar en segundo lugar qué posibles datos podría aportar la ciencia que sirvieran de base para justificar esas opiniones filosóficas, datos científicos que pusieran pues en jaque la posibilidad misma de la religión.

Ningún conocimiento científico puede implicar 0), pues 0) incluye en particular la posibilidad misma del conocimiento científico. Ni tampoco puede implicar 1). La razón es que ningún conocimiento de la experiencia sensible o científica puede determinar que haya, o que no haya, más realidad que la experimentada por los sentidos o por esa prolongación de ellos que es la ciencia experimental. El científico que niegue que hay algo más que la materia (en ese lato sentido filosófico que incluye también la energía) puede hacerlo con todo derecho, pues todo hombre tiene derecho a pensar y a filosofar, pero no a decir que a esa conclusión filosófica suya haya llegado por dato alguno de la ciencia (y a quien eso afirme, habría que preguntarle cuál sea ese dato, pregunta que quedará sin respuesta). $\mathrm{Ni}$ tampoco puede ningún dato de la ciencia presentar al mundo como filosóficamente eterno, ya que la eternidad filosófica no es ausencia de principio ni de fin, sino ausencia de tiempo, y el mundo que estudia la física es precisamente el espacio-tiempo.

Por eliminación, llegamos pues a que tan sólo una física que presente el comportamiento de la materia como determinista serviría de apoyo a un determinismo filosófico por el que el futuro estuviese determinado por el presente haciendo imposible la acción libre de Dios y del hombre sobre el mundo (Providencia y libre albedrío), algo ya reseñado en 2) como necesario para la religión.

La pregunta que surge entonces, en tercer lugar, es la siguiente: ¿es el determinismo de la materia un dato de la física? La respuesta es negati- 
va, pues en la Mecánica Cuántica hay indeterminismo (no en la evolución temporal de los sistemas cuánticos, sino en cada observación), y aunque sabemos que la Mecánica Cuántica es teoría provisional, también sabemos por los datos experimentales sobre entrelazamiento cuántico de Alain Aspect en los años setenta (violación de las desigualdades de Bell) que cualquier teoría futura, y en particular la tan esperada teoría que unifique las cuatro fuerzas de la naturaleza (que hoy son aún 3+1), deberá incorporar el indeterminismo cuántico como aleatoriedad intrínseca. E incluso, como ya he comentado, sabemos hoy que ni siquiera la mecánica clásica era determinista, como se creía.

Se comprende así que Pascual Jordan, uno de los pioneros de la Mecánica Cuántica, llegase a la página final de su obra "El hombre de ciencia ante el problema religioso” (Jordan 1972), sin haber escrito una palabra sobre religión -tan sólo divulgación científica, algo que, a vista del título, desconcierta al lector-, diciendo estas palabras:

No sin razón he titulado este libro El hombre de ciencia ante el problema religioso. Su intención era explicar cómo todos los muros que la ciencia antigua había levantado para obstruir el camino de acceso a la religión hoy han desaparecido. Pero ahí encuentra también sus límites la pretensión de este libro; de ningún modo era tarea suya exponer lo que nos espera si de hecho nos adentramos por ese camino que vuelve a estar libre. Nos conformamos con haber mostrado que el camino esta expedito. La competencia del autor acaba ahí, nos quedamos ante la religión, sin hablar de ella más de lo necesario para reconocer ese camino cuya viabilidad intentábamos examinar.

Este listado, asombrosamente breve para los no avisados, debería ser complementado con los problemas que la ciencia podría poner directamente a la religión, sin pasar por ningún problema filosófico, y por tanto sólo problema para el credo de una religión en particular. Tomando la mía propia, el cristianismo, sólo se me ocurre uno: la doctrina del pecado original, esencial para la idea de redención, parece exigir que haya habido una pareja humana -aquélla para la que el pecado original fuera pecado personal-de la cual descendamos todos los hombres y mujeres actuales. En caso con- 
trario habría que leer la Biblia muy interpretativamente en el sentido de que "los primeros hombres pecaron o se alejaron de Dios". Pero al menos la ciencia no nos fuerza a esto, pues de hecho la biología molecular actual ha encontrado -al secuenciar el ADN mitocondrial (no alterado al pasar de madres a hijas) - que hay por lo menos una pareja de la que todos los hombres actuales descendemos (esto es compatible con el dato de que haya de hecho varias parejas de cada una de las cuales descendemos todos, pues basta que una de ellas pecase para que toda la humanidad actual sufra, según el designio divino, las consecuencias de ese pecado personal) ${ }^{10}$.

No he incluido en este último apartado, como alguien hubiera esperado, la negación del origen temporal del universo como posible obstáculo, no filosófico pero sí científico, para la creencia en un Dios creador (que el tiempo tenga un origen o sea circular, o ilimitado, es cuestión científica, pues la filosofía no conoce más eternidad que la ausencia de tiempo). Y es que tal negación, si a ello llegara un día la ciencia, no estaría en contradicción con las palabras primeras de la Biblia: “Al principio creó Dios los cielos y la tierra”. Con parecidas palabras, el Concilio Vaticano I cita literalmente al Concilio IV de Letrán: “Desde el principio creó de la nada a una y otra criatura, la espiritual y la corporal, es decir, la angélica y la mundana” (Denzinger and Hünermann 1999, n. 3002). Esto no es una definición dogmática en el sentido de que ese principio se haya

10 Escribe Pío XII: "Los fieles no pueden abrazar la sentencia de los que afirman o que después de Adán existieron en la tierra verdaderos hombres que no procedieron de aquél como el primer padre de todos por generación natural, o que Adán significa una muchedumbre de primeros padres. No se ve por modo alguno cómo puede esta sentencia conciliarse con lo que las fuentes de la verdad revelada y los documentos del magisterio de la Iglesia proponen sobre el pecado original, que procede del pecado verdaderamente cometido por un solo Adán y que, transfundido a todos por generación, es propio a cada uno" (Encíclica Humani Generis, 17). Ciertamente, la expresión "no se ve por modo alguno cómo puede esta sentencia conciliarse" no es la forma de una definición dogmática. Advertimos al lector no familiarizado que, aunque ha habido muchas encíclicas, sólo en el 12 de Agosto de 1950 ha habido una definición dogmática de la Iglesia Católica después de la declaración del dogma de la infalibilidad en el Concilio Vaticano I de 1870: "Proclamamos, declaramos y definimos ser dogma divinamente revelado: Que la Inmaculada Madre de Dios, siempre Virgen María, cumplido el curso de su vida terrestre, fue asunta en cuerpo y alma a la gloria celestial” 
de entender como cronológico sino que es un referirse a la creación de la nada -esto sí es dogmático- con las mismas palabras que el Génesis. La razón es que no leemos las palabras de la religión como datos de la ciencia física, sino en su sentido ontológico, es decir como afirmando que todo ser tiene a Dios como causa primera. Como dice explícitamente Santo Tomás, no hay que entenderla como cronológicamente primera (como la entiende y divulga Stephen Hawking), sino ontológicamente primera, es decir como aquella causa de la cual dice el santo en su exposición de las cinco vías en su "Suma contra Gentiles”, que, retirada ella, cesan todas las causas intermedias en su causación. De hecho, la única afirmación explícita de que el mundo no es eterno está en un sínodo del siglo VI, que parece fue sancionado por el Papa, y en el que sólo se condena a quien afirme que el mundo es ¡coeterno con Dios! ${ }^{11}$. Es decir que se habla de eternidad filosófica, ausencia de tiempo, algo que nunca podrá ser afirmado ni negado por la física, que precisamente tiene que habérselas con el espacio-tiempo.

Es ahora cuando podemos contestar, sin excesivo esfuerzo, a Alan Turing, Jacques Monod y Stephen Hawking.

Si el hombre fuera una máquina, o si su comportamiento apareciese ante nosotros indistinguible del de una máquina, como dice Turing, ciertamente el comportamiento humano sería determinista, pues así es el comportamiento de las máquinas. Pero cuando esto decía Turing no se trataba de ciencia real sino de una profecía a cincuenta años vista que no se ha cumplido ni se va a cumplir, pues sabemos ahora que el hombre no es una máquina, en el sentido técnico de Turing, de "máquina secuencial": En efecto, sabemos que para cualquier máquina secuencial, o algoritmo, existe una pregunta que ella no puede responder (es decir que al iniciarse el algoritmo con ese input no llega nunca a emitir una respuesta como

${ }_{11}$ Así lo dice Casiodoro en sus famosas “Institutiones”: que el Papa Vigilio aprobó las conclusiones del Sínodo de Constantinopla de 543. En él se aprobaban los anatemas dictados por el emperador Justiniano, el octavo de los cuales decía: "Si alguno dice o siente que el poder de Dios es limitado y que sólo obró en la creación cuanto pudo abarcar y pensar, o que las creaturas son coeternas a Dios, sea anatema" (Denzinger and Hünermann 1999, n. 410).

Scientia $e t$ Fides $1(1) / 2013$ 
output) y que, sin embargo, quien pone la pregunta sí sabe responder, por lo que él mismo no es esa máquina. En consecuencia, si el cerebro humano, con el que el espíritu pudiera ser compatible según una filosofía no materialista, fuera describible como una máquina, no podría ser ésta máquina secuencial, es decir máquina en el sentido de Turing. Penrose hizo en su obra divulgadora "La nueva mente del emperador" (Penrose 1991) una muy clara divulgación de este argumento, sujeto actual de debate -filosóficoentre los expertos en Inteligencia Artificial. Por ser pues tema en debate, me parece más interesante esta otra línea (también recordada por Penrose): Hay bastante datos en neurobiología que apuntan hacia fenómenos cuánticos en nuestros procesos de emisión de respuesta, siendo las distancias entre las moléculas responsables las adecuadas para ese tipo de fenómenos (Kauffman 2003; 2009). Pero una máquina cuántica no sería ya determinista, y por tanto un cerebro así no estaría ya cerrado a la posibilidad de libertad y responsabilidad moral.

En cuanto a la objeción de Monod, digamos que, precisamente porque la ciencia actual nos ofrece una imagen del universo hecha no sólo de necesidad sino también de azar ${ }^{12}$, esa imagen científica es compatible con una filosofía de la libertad y ésta con la responsabilidad moral que suponen las religiones. En otras palabras, queda abierta la posibilidad de que sea el espíritu, humano o divino (providencia), quien determine ese azar, ya que sabemos que no lo determina ninguna realidad física. Es más, si unimos al indeterminismo físico el principio filosófico (llamado “de razón suficiente” por Leibniz) de que hay explicación de cuanto es y ocurre -la conozca o no el hombre-, de modo que nada existe por azar ni nada ocurre por azar, ob-

12 Chaitin ha definido una sucesión de azar como aquella que no puede ser producida por un algoritmo o máquina expresable en menos dígitos que ella (Chaitin 1975). Una sucesión generada al azar puede no ser de azar, por ejemplo, si lanzo muchas veces los dados y la sucesión que obtengo son unos y doses alternados. O si saco letras al azar de un bombo y sale una novela tan cabal como el Quijote. Pues bien, Chaitin ha probado que no se puede demostrar que una sucesión sea de azar. Por tanto, lo que la ciencia sabe acerca de las mutaciones de las secuencias de $\mathrm{ADN}$ es que son producidas por un procedimiento de azar -el de la Mecánica Cuántica- pero no podrá nunca demostrar que sean de azar, como creía Jacques Monod (aunque no disturbaría que lo fueran, creo que es importante reseñarlo). 
tenemos entonces, como conclusión filosófica, que hay más realidad que la meramente material, a saber aquella que determina lo que la física deja al azar (más precisamente: gracias al dato de la Mecánica Cuántica -que no es dato provisional sino que deberá asumir toda teoría futura- según el cual toda observación, a nivel cuántico, es intrínsecamente aleatoria, sabemos ahora que el principio de racionalidad o de razón suficiente implica la existencia del espíritu, entendiendo por tal cualquier realidad no material. Por tanto, es la negación del espíritu, y no su afirmación, lo que entraña irracionalidad). Tampoco me parece que vaya contra la finalidad y contra la posibilidad de existencia de plan para el mundo viviente la visión darwiniana que lo entiende como mezcla de la necesidad de sus leyes biológicas, y del azar de sus mutaciones. Si el orden que en el mundo admiramos lo ha dejado el Creador en leyes muy simples, que estudia la ciencia, tanto más admirable es por ello, como expresa el propio Darwin al final de su obra “El origen de las especies” (Darwin 1859):

Hay una grandiosidad en esta visión de la vida, con sus diversos poderes, habiendo recibido el aliento original del Creador (having been originally breathed by the Creator) en unas pocas formas o en una sola; y en que, mientras este planeta rodaba siguiendo la ley fija de la gravedad, hayan evolucionado y estén evolucionando desde un comienzo tan simple un sin fin de formas bellísimas y maravillosas.

En cuanto a la voz impedida pero con admiración escuchada de Stephen Hawking, creo que sólo puede crear problemas a la religión del lector de escasa formación -científica, filosófica y religiosa-, pues Hawking no distingue lo que es afirmación filosófica de lo que es afirmación científica, o si una afirmación es o no realmente incompatible con la religión, y aunque en alguna ocasión dice que lo suyo es sólo una propuesta, esto pronto lo olvida el lego lector, y llega a tomar la exposición de la propuesta como si fuera ciencia tan establecida como la previamente divulgada. Nada que haga referencia al universo antes de diez elevado a menos cuarenta y tres segundos es ciencia establecida, ni siquiera ciencia conjetural -pues las conjeturas físicas son hipótesis que van acompañadas de su cortejo de 
fórmulas-, puesto que no tenemos una física unificada que permita comprender nada antes de ese instante: que haya o no un punto singular en el inicio del espacio-tiempo (es decir un Big-Bang propiamente dicho); que los fotones que aparecen en equilibrio con los pares materia-antimateria al abrirse el telón del escenario conocido procedan por implosión de un universo anterior o por fluctuaciones cuánticas del vacío. Nada de esto puede saber la ciencia actualmente establecida, pues nada sabe anterior a ese instante antes del cual la gravedad estaba unificada con las demás fuerzas. Los universos o variedades 4-dimensionales riemannianas compactas en superposición cuántica coherente no son tampoco ciencia establecida porque "riemanniano + superposición cuántica” es "relatividad general + mecánica cuántica”, o sea, gravedad cuántica, una teoría de la que no disponemos en la actualidad. En su divulgación más reciente ha hablado Hawking también de la teoría de cuerdas, en las que los entes elementales no serían partículas, sino cuerdas vibrando en diez dimensiones, seis de ellas no expandidas tras el Big-Bang, quedando pues las cuatro dimensiones conocidas. Pero aunque esta teoría merece por lo menos el nombre de ciencia conjetural, pues llega con su cortejo de matemáticas (y majestuosas matemáticas: las superficies de Riemann o curvas algebraicas), con todo, no puede decirse en modo alguno - ¡muy desgraciadamente!- que se trate de ciencia establecida.

Nada desde lo que Stephen Hawking filosofa (isin decir que filosofa!) en sus libros de divulgación científica, es de hecho ciencia establecida, por lo que propiamente no debería contestar a ello en esta sección, pero lo haré, porque es pregunta que ha turbado a muchas personas: “¿Qué papel juega ya el Creador?” Ya adelanté, en la sección primera, la respuesta: Ninguno. Como no jugaba ningún papel antes de su propuesta. El Creador no juega ningún papel en la ciencia física, ni entonces, ni antes, ni nunca. No creemos en Él porque la velocidad inicial del universo sea tal o cual (de lo que probablemente el lector se haya enterado ahora) sino porque hay ser en vez de nada. ¡Nada! La nada de la que nada sale. La nada muy distinta del vacío cuántico con sus fluctuaciones con probabilidad dada por la integral de Feynman. Es propio de la física estudiar el "cómo" del inicio del universo pero no el "por qué" del universo -"por qué el ser en vez de la nada”- pues 
esta pregunta es filosófica (éste es esencialmente el sentido de las palabras de Juan Pablo II acerca del origen del universo, al distinguir entre cuestión física y cuestión metafísica en una alocución a los cosmólogos ${ }^{13}$ ). En particular, los creyentes no nos sentimos incómodos con un universo que proceda de otro anterior, o con un universo cíclico, o con un universo que proceda de fluctuaciones cuánticas del vacío, o con un universo superposición cuántica de muchos universos posibles -la cual colapsáramos al observar el universo actual- o con un universo hecho de cuerdas en vez de partículas. Cualquiera de ellos, ciclos, vacío cuántico y sus fluctuaciones, superposiciones cuánticas de universos, o cuerdas en diez dimensiones, lo veremos sin problema como obra de Dios cuando la investigación llegue a convertirlo en ciencia establecida.

Lo mismo podría decir de la propuesta emparentada de Everett según la cual la explicación, no ciertamente física, de que en una observación cuántica salga un resultado en vez de otros también probables, estaría en que también salen esos otros resultados, de modo que en cada observación cuántica se producen bifurcaciones a otros universos distintos del nuestro. Está bien como especulación, pero hay que dejar claro a los legos que esto no es ciencia -ciencia experimentalmente falsable- pues si se diese tal bifurcación a otros universos, nada podríamos afirmar ni negar de esos universos con nuestra ciencia, cuyas leyes sólo tratan de nuestro universo. Si además hay otros, no sabemos qué leyes tendrían, ni siquiera si tendrían

13 Así lo divulga Hawking en su "Breve historia del tiempo": "Nos dijo que estaba bien estudiar la evolución del universo después del Big-Bang, pero que no deberíamos investigar en el mismo Big-Bang porque ése es el momento de la Creación y por tanto la obra de Dios. Me alegré entonces de que no conociese el tema de la charla que yo acababa de dar en el congreso: la posibilidad de que el espacio-tiempo fuese finito pero no tuviese ninguna frontera lo que significaría que no hubo ningún principio, ningún momento de Creación. ¡Yo no tenía ningún deseo de compartir el destino de Galileo, con quien me siento fuertemente identificado en parte por la coincidencia de haber nacido exactamente 300 años después de su muerte!” Las palabras del Papa en ese congreso sobre Cosmología organizados por los jesuitas en el Vaticano, en 1981, fueron éstas: “Toda hipótesis científica sobre el origen del mundo, como la de un átomo primitivo, del que procedería todo el universo físico, deja abierto el problema referente al comienzo del universo. La ciencia no puede por sí misma resolver esa cuestión; hace falta ese saber del hombre que se eleva por encima de la física y la astrofísica y que lleva el nombre de metafísica”. 
leyes. Pero filosóficamente tampoco sería esto problema para quienes creen en Dios, pues se vería entonces en Dios la causa primera también de esos otros universos, la causa del ser en vez de la nada.

Sin embargo estas especulaciones que ningún problema plantean al científico, turban mucho a personas que saben poco de ciencia y que las toman por cosa poco menos que comprobada. Y toman también por cosa de ciencia las afirmaciones de carácter filosófico que pueda hacer cualquier científico, sobre todo si no es honesto y las hace pasar, ante quienes nada saben, como conclusiones científicas.

En realidad el científico, o los hombres que saben algo de ciencia, tienen más motivos, más amplio campo desde el que arrancar su especulación filosófica, levantando su mente por encima de la mera materialidad. Me apena por eso que esta grandiosa imagen lograda con el trabajo de tantos, y en particular de tantos creyentes, venga a ser falseada con elementos subjetivos que ya no son ciencia, pero que son interpretados como tal para quienes nada saben de ella. La gente más cultivada, aunque no sean personas de ciencia, sospechan al menos. Pero la gente más sencilla, el blanco más fácil, es la que lleva la peor parte. Y a unos y a otros se les roba así, con una manipulación espuria, el ancho camino hacia la más gozosa y profunda verdad de que no estamos solos en el universo; la realidad de la divinidad. Se entiende que Louis Pasteur dijera: "La poca ciencia aleja de Dios. La mucha ciencia devuelve a Él”.

\section{Conclusiones para una actualizada Filosofía de la Naturaleza}

He expresado mi opinión negativa sobre algunas conclusiones filosóficas sobre datos científicos, pero está bien que se saquen conclusiones, mientras no se hagan pasar por ciencia, sino presentadas como lo que son, como filosofía. Quizá el lector pueda preguntar, no en negativo, no en respuesta a estas opiniones en realidad filosóficas, sino en positivo, cuáles son las mías propias, qué conclusiones filosóficas extraería yo de la imagen del mundo que he descrito como aportada por la ciencia. En realidad ya he mencionado varias de esas conclusiones, que quizá podrían servir para construir 
una filosofía de la naturaleza actualizada, es decir basada en la imagen de la naturaleza que nos presenta la ciencia actualmente establecida:

0) Como los científicos han entrado en la arena filosófica, fundamentalmente en obras de divulgación (las verdaderas obras de filosofía actuales), el realismo ha sido devuelto a la filosofía por vía de hecho y sin que los protagonistas lo adviertan. Se ha devuelto a la filosofía "la realidad", y nuestro poder "conocer" algo de ella, elementos progresivamente perdidos desde la duda cartesiana. Como la ciencia de la naturaleza nació en el seno de la filosofía cristiana, no es de extrañar que estos elementos esenciales en la filosofía cristiana hayan sido recuperados con naturalidad en el filosofar desde la imagen de la naturaleza que esa misma ciencia nos aporta. Creo que no sólo se recupera con naturalidad el realismo, sino también otros elementos básicos que a continuación describiré.

1) Debido a la indeterminación en Mecánica Cuántica, si admitimos filosóficamente el principio de causalidad o, en su formulación racional por Leibniz, el principio de razón suficiente por el que todo lo que es tiene una razón de ser y de ser como es, y todo lo que sucede tiene una razón para haber sucedido y de haber sucedido como ha sucedido, entonces tenemos que admitir que hay más realidad que la meramente material ("entonces": se trata pues de una implicación). En efecto, si tiene que haber una causa de que haya salido un resultado en vez de otro, ambos probables, en una medida cuántica, como esa causa no puede tener realidad física, hay entonces más realidad que la meramente física.

2) Recuerda Chaitin en su reciente obra "Proving Darwin" (Chaitin 2012) que: "Según Leibniz, Discours de metaphysique, secciones V y VI, el mundo es menos perfecto si Dios ha tenido que intervenir en él para crear la Vida. Un mundo que requiriese milagros es menos perfecto que un mundo que corre por su cuenta, porque esto es más complicado”. Hemos visto esta misma idea en la cita final de Charles Darwin en su obra "Origen de las Especies”. Siendo la indeterminación cuántica la causa de las mutaciones genéticas (la versión mutada también tiene una cierta probabilidad, según la mecánica cuántica), la intervención de Dios en el origen de la vida y en su evolución, y hasta su Providencia, no aparece ya como un mi- 
lagro -algo que suspendiera las leyes de la física- sino como algo previsto por esas mismas leyes. Sin embargo, nunca podremos saber, con la ciencia en la mano, si esa intervención se ha dado, como nunca podremos saber con la ciencia en la mano, si la sucesión de letras del Quijote, con tanta "forma" y tan buen sentido, ha sido generada o no por un proceso de azar. Ciertamente, el Quijote no es sucesión de azar -en el sentido de ausencia de forma, matemáticamente precisado por Chaitin-, pero podría haber sido generado por un proceso de azar (como al lanzar los lados un millón de veces, si sale par, impar, par, impar, etc... Hay forma en la sucesión, aunque el proceso utilizado haya sido de azar). Aquí sucede al revés que en el caso del Quijote del que no sabemos si ha salido de un bombo: lo que sabemos de la sucesión de mutaciones por las que ha emergido la forma en la vida es que se ha generado por un procedimiento de azar, pero es matemáticamente indemostrable que se trate de una sucesión de azar, es decir que no haya forma en ella. Y es que (aunque puede demostrarse que una sucesión de números no es de azar, encontrando alguna forma o ley de formación en ella) por el celebrado teorema de Chaitin, no puede demostrarse que una sucesión dada de números sea de azar (Chaitin 1975). La idea de aplicar el teorema de Chaitin a la filosofía de la evolución ha sido sugerida por Fernando Sols (F. Sols 2012) ${ }^{14}$.

Nunca podremos tener como dato de la ciencia que a la forma de la vida se haya llegado como resultado final de mutaciones azarosas y de

14 Quizá sea éste el momento de decir algo sobre la famosa tesis del "diseño inteligente", que aboga por la existencia de forma -lo contrario al azar- en el resultado de las mutaciones, y de forma que ha emergido sin explicación científica alguna (sólo explicable, pues, como diseñada por una inteligencia, en clara alusión a la inteligencia divina). Esta tesis no es científicamente demostrable, pues si se mostrase la existencia de forma en el resultado de las mutaciones, aunque pueda no haber explicación científica en la actualidad, siempre quedará abierta la posibilidad de explicación científica en el futuro. Ni tampoco es científicamente demostrable, como hemos visto, la tesis contraria, o sea la que aboga porque el resultado de las mutaciones es de azar, puesto que el azar no puede ser demostrado, sino sólo que el procedimiento haya sido de azar. Como ni la hipótesis del diseño inteligente ni su contraria son científicamente demostrables, ninguna de las dos es científicamente falsable, por lo que, según el criterio de Popper, ninguna de las dos es científica, sino tesis filosófica. Como el diálogo -o más bien discusión- entre ambas tesis suele conducirse, sin embargo, en términos científicos, resulta pues interminable. 
selección natural, puesto que el azar no puede ser demostrado. Tan sólo sabemos que el procedimiento ha sido de azar ( $\mathrm{Y}$ Y nada menos que el azar de la Mecánica Cuántica!). Queda pues abierta la posibilidad -no física sino filosófica- de que haya habido una causa por la que ese aparente azar no haya sido realmente azaroso. Según Leibniz, el azar filosófico, como ausencia de toda explicación, no se da, sino que sólo se da nuestra ignorancia de tal explicación. Y hasta el gran escéptico David Hume lo afirma así en su “Investigación sobre el entendimiento humano”, en el capítulo sobre la probabilidad: "Aunque no exista en el mundo tal cosa como el azar, nuestra ignorancia de la causa real de cualquier evento tiene la misma influencia sobre el entendimiento, dando lugar a una especie parecida de creencia u opinión” (Hume 1981, c. VI, n. 1).

3) Algo parecido puede decirse sobre nuestra libertad y consecuente responsabilidad moral. La concepción filosófica del hombre como cuerpo y alma racional, entendiendo por tal su principio de vida no sólo vegetal y animal, sino también racional, no es obstáculo para que ese cuerpo y ese principio de vida, en lo que tiene de vegetal y animal, es decir en lo que el hombre tiene de realidad común con los animales, sea contemplado por la ciencia como una mera máquina. Pero esto no significa que haya de ser contemplado por la ciencia como una máquina secuencial, lo que implicaría un comportamiento determinista incompatible con un alma racional y libre, es decir, con el espíritu. De hecho, la propia ciencia nos proporciona hoy una razón teórica, como he recordado, por la que no puede ser una máquina secuencial, y hay cierta evidencia experimental de que fenómenos cognoscitivos y volitivos se producen a nivel cuántico y por tanto con indeterminación y sin problema, pues, de incompatibilidad con el espíritu, con la libertad y con la responsabilidad moral (no es pertinente hablar de “máquina cuántica” porque la informática cuántica es sólo una ciencia en desarrollo, aunque ya se piensa en ella como la informática del futuro). Si somos verdadera causa de nuestros actos y decisiones -de nuevo, si hay en ellas más que mero azar-, entonces nos vemos obligado a admitir, como afirmación filosófica, que hay más realidad en nosotros que esa máquina cuántica, como quizá llegue un día a describir la ciencia nuestro cerebro, 
máquina compatible con esa otra realidad espiritual a la que llamamos alma humana.

Sabemos por un teorema de Gödel que no hay ninguna máquina o algoritmo -ningún "oráculo"- que pueda decidir si cualquier proposición matemática se deduce o no de los axiomas que hemos puesto como base de la matemática, es decir si es lógicamente derivable de esos axiomas (una máquina que siempre llega a pararse, emitiendo entonces la respuesta correcta a esta pregunta). Sin embargo, sí que hay una máquina que dé respuesta positiva si la proposición es un teorema, respuesta negativa si la negación de la proposición es un teorema, pero no se pare nunca si ni la proposición ni su negación son un teorema de la teoría. Con todo, un oráculo así no serviría para hacer matemáticas, pues si la máquina aún no se ha parado no podemos saber si es porque tarda la respuesta o porque nunca se va a parar. En cierto modo esa máquina es como un matemático que no ha encontrado aún la demostración de la proposición que busca, pero tampoco demostración de su negación. Nuestro cuidado matemático no sabe si es porque no existe demostración ni de la proposición ni de su negación, o es porque no se le ha ocurrido. (Por el primer teorema de Gödel que hemos enunciado, la teoría de conjuntos, es decir la matemática, no es completa: hay proposiciones tales que ni ella ni su negación son teorema).

Sin embargo, todo matemático que ha investigado sabe por experiencia que sigue un algoritmo (= actúa como una máquina) cuando expone la demostración ya encontrada de un teorema, pero no cuando busca esa demostración, pues entonces se guía por analogías, intuiciones, corazonadas, golpes de fortuna. La invención de una demostración -el verdadero pensamiento matemático- no parece modelizable por un algoritmo o máquina secuencial. El razonamiento lógico ha tomado al pensamiento matemático como paradigma, pero este pensamiento, en lo que tiene de capacidad creativa, no parece modelizable por máquina alguna, al menos mientras nos restrinjamos a las actuales máquinas secuenciales, simulables por una máquina de Turing. Hay en la intuición creadora del matemático y en todo el pensamiento humano un elemento que, en caso de ser modelizado por una máquina, debería ser máquina no secuencial, probablemente una má- 
quina que incorporara la indeterminación cuántica, algo coherente con los datos del actual estudio del cerebro (Kauffman 2009). Creo que urge una actualizada descripción del método matemático, y en general del método de las ciencias deductivas, que distinga bien entre la deducción desde los postulados de una teoría y el pensamiento humano que ha llegado a encontrar esa deducción, una descripción en la que quepa, y en la que ocupe un lugar preferente, la conjetura.

4) Habiendo recuperado en estas consideraciones anteriores -especulación filosófica sobre la naturaleza tal como nos la presenta hoy la ciencia- la causa eficiente y libre, y por tanto la causa final, podemos concluir estas consideraciones observando que también la causa formal y la causa material son recuperadas por esta imagen actual de la naturaleza. Aristóteles entiende por causa formal de un ser corporal su forma como principio o causa de su ser, es decir forma-en-la-materia, como la pone el hilemorfismo, y no sólo forma en nuestro conocimiento de la realidad natural, como serían las formas a priori de Kant, o las formas de las leyes físicas según las epistemologías de inspiración kantiana, como si estas leyes nada describiesen que esté en la naturaleza. Esta recuperación de la causa formal en filosofía es absolutamente necesaria para una actualizada epistemología de la ciencia en la era informática, después que Alan Turing distinguió en 1939 entre hardware y software -versión actual de la materia y de la forma- de modo que un mismo hardware puede soportar distintos softwares, y un mismo software puede in-formar o "dar forma a” distintos hardwares.

Esta recuperación de la forma surge de modo natural en la reflexión filosófica tanto sobre la imagen del mundo en la física actual como en la química o la biología, y muy en particular en la biogenética, como in-formática evolutiva de la vida, pues todas éstas estudian diversos grados o niveles de forma en la naturaleza, niveles que se dan en la forma de un solo $\operatorname{ser}^{15}$ (Arana 2012). Yo, por ejemplo, tengo una realidad física, química y bio-

15 Santo Tomas, en De anima, a. 9 c, viene a hablar de grados superiores e inferiores en la forma, o al menos en su actualización en la materia: "Quodammodo una et eadem forma, secundum quod constituit materiam in actu inferiores gradus, est media inter materiam et seipsam, secundum quod constituit eam in actu superioris gradus.

Scientia $e t$ Fides $1(1) / 2013$ 
lógica, o digamos que el método de estas ciencias estudia esos distintos grados o niveles de forma que se dan en mí (como una misma onda electromagnética puede transportar "in-formaciones" muy distintas en distintas frecuencias, por ejemplo, melodías distintas y conversaciones en diversos idiomas).

Pero hay más forma en mí que la correspondiente a esos niveles que estudian las ciencias experimentales, pues hay más que decir sobre la realidad de un hombre que la descrita por todas esas ciencias juntas, y en particular más de lo que pueda decir la biología molecular. Una persona es más que la información de su ADN. La misma biología pone ya una diferencia: un animal no es sólo su genotipo, sino también su fenotipo. Pone una diferencia también la filosofía: cuando una mujer alumbra dos gemelos idénticos, aunque ambos tienen el mismo genotipo y, de momento, el mismo fenotipo, son sin embargo dos personas distintas. Y pone una diferencia también la religión, lo que explicaré de modo muy crudo con la siguiente experiencia mental: una vez descrito el genoma humano, es pensable -valga de momento como "Gedankenexperiment"- que puedan sintetizarse en laboratorio veintitrés pares de cromosomas humanos; y es pensable que, inyectados éstos en el núcleo del óvulo de una mona, previamente vaciado de cromosomas, pudiese éste fijarse en su placenta como óvulo fecundado. Si se consiguiese que ese óvulo artificialmente fecundado fuese viable hasta desarrollar un ser vivo en el útero de la mona, ¿sería éste una persona humana? No ha habido en su génesis más que un laboratorio y un animal, ninguna persona. La contestación de la religión ya fue dada en la Humani generis (Denzinger and Hünermann 1999, nn. 3875ss) al afirmar que el cuerpo humano -esencialmente la información del ADN humano- bien puede ser el resultado de la evolución (al fin y al cabo, barro de la tierra) pero no así su alma espiritual, realidad muy distinta: soplo divino sobre ese barro cada vez que una vida humana comienza. A lo que un científico pudiera fabricar le faltaría ese soplo, y ese soplo por el que habría allí un hombre sólo lo habría si Dios quisiera darlo. (Podría plantearse entonces el problema de si ese hombre tendría pecado original, pues no sería descendiente de Adán y Eva ni de hombre y mujer alguno, sino de 
un laboratorio y una mona, pero ya pensaremos en ese tema teológico -en absoluto filosófico- si alguna vez alguien hace realidad este experimento, práctica por supuesto profundamente inmoral pues el científico se estaría autoasignando el papel de Dios, aunque práctica que hubiera hecho las delicias de nazis y buscadores del superhombre).

Cuando yo capto algo de esa forma a cualquiera de estos niveles, pasa ésta a ser forma en mi entendimiento, y en esa captación consiste el conocer, bien descrito como "coactualidad de formas". La materia queda entonces como mero soporte de formas, y no es muy distinto lo que afirmaban los filósofos antiguos al decir que la materia es pura incognoscibilidad, que lo afirmado por quienes modernamente filosofan acerca de las partículas elementales: sabemos que su forma, lo inteligible de ellas, todo lo que de ellas podemos saber, viene dado por una función matemática -su “función de onda" - pero nada sabemos, y debemos guardar silencio, acerca de lo que la partícula “es".

En consecuencia, creo que la filosofía aristotélica es la más adecuada, no sólo para una epistemología actualizada de las ciencias -algo que ya he apuntado-, sino también para una filosofía de la naturaleza que arranque de la imagen del mundo que hoy nos presentan las ciencias. Y es natural que sea así, pues la filosofía de Aristóteles viene a ser una formalización del sentido común humano, el cual ha sido forjado en la observación de la naturaleza. Alguien querría incluir aquí la filosofía platónica para que este cuadro resultase inclusivo de las matemáticas, pero una lectura comprensiva de los catorce libros de la Metafísica de Aristóteles (Aristóteles 1970) lleva a entender que su iterado rechazo de las "ideas separadas" platónicas, no es un rechazo plano de las “ideas”, puesto que él entiende que hay "idea” en cada ser -lo que el medievo tradujo como "esencia”(aunque en realidad se habría de traducir por “lo visto”). Aristóteles sólo rechaza que se den esas ideas en un "topos uranos” o mundo separado, algo que el actual platónico o platonizante interpreta como mito o metáfora (Whitehead, Gödel, Hardy). Evidentemente, no se trata aquí de un aristotelismo que se pierda en divisiones y subdivisiones de escuela, cosificando lo que para Aristóteles no eran más que modos de hablar -aunque modos que en 
algo se corresponden con aspectos de la realidad-, sino un aristotelismo que profundice en las grandes intuiciones del estagirita, como aquélla que pone un principio determinante -la forma- y un principio determinable -la materia- en todo ser corpóreo, o la vigorosa apuesta aristotélica por la capacidad cognoscitiva del entendimiento humano (verdaderamente cognoscitiva en su coactualidad de formas, no formas que ponga uno mismo, como en el apriorismo kantiano). No sin razón dice Werner Heisenberg en su "Phisik und Philosophie" (Heisenberg 1945) que una buena filosofía conduce a una buena física y una mala filosofía conduce a una mala física, en lo que entiende por mala filosofía la concepción cartesiana en la que espíritu y materia son vistas como realidades separadas, la cual contrapone Heisenberg a la concepción hilemórfica de Aristóteles -que ve el alma como la forma sustancial del ser corpóreo-, algo en lo que ve una mejor filosofía.

Por eso la actual ciencia puede entrar fácilmente en diálogo, como reflexión humana que la complementa, con la filosofía aristotélica, pero muy difícilmente con la duda cartesiana sobre la realidad y sobre la capacidad humana de conocerla (lo que ha quedado de Descartes, pues el modo en que él mismo resuelve esa duda pocos lo han admitido luego). Pero la filosofía, normalmente implícita, en la actual divulgación de la ciencia, incluso en las divulgaciones materialistas, es una filosofía realista -ontológica y gnoseológicamente realista- que ignora la duda metódica cartesiana y en consecuencia la filosofía que siguió a su planteamiento crítico.

En particular, es casi imposible el diálogo de la física con una filosofía (Hume) que sólo ve cualidades sensibles pero no algo de lo que sean cualidades -negación moderna de la sustancia- o que no admite que algunos fenómenos naturales puedan ser explicados por otros fenómenos naturales -negación moderna de la relación causal-, pues este tipo de explicaciones constituyen la esencia misma de la ciencia experimental. Y la imagen que del mundo nos proporciona la ciencia experimental es incompatible con la filosofía de Kant para quien la forma está en el propio conocimiento humano, no en la naturaleza. ¿En qué entendimiento humano está, a priori, de nacimiento, la curvatura del espacio-tiempo en que consiste la fuerza de la gravedad según la relatividad general, si a duras penas podrá com- 
prender esta curvatura el lector ayuno de geometría diferencial? Y sin embargo, es forma innegable en la naturaleza según la física actual, que deberá incorporar la física unificada si algún día llegamos a ella. En cuanto a la filosofía contemporánea -idealismo, vitalismo, materialismo dialéctico- desembocadura natural de aquella filosofía moderna, difícilmente podrá dialogar con la ciencia como puede hacerlo la visión hilemórfica de la naturaleza en la filosofía aristotélica. Pensemos por ejemplo en la base conceptual que puede proporcionar a la ciencia experimental la filosofía de Schopenhauer o de Nietzsche. Y, paradójicamente, el positivismo, a pesar de algunas afirmaciones de Compte (en realidad contradictorias) según las cuales la filosofía sobreviviría en la era científica como pura epistemología de las ciencias, al negar esencialmente la filosofía está socavando las bases para una verdadera epistemología de las ciencias, pues éstas sólo pueden ser filosóficas. No por casualidad Planck y Einstein fueron positivistas en su juventud, pero rechazaron el positivismo en su pensamiento de madurez.

En cuanto a la fenomenología, aquel esfuerzo titánico por romper el cerco del escepticismo, puede establecer un diálogo adecuado con las matemáticas, pero quizá haya que restringirse al Husserl de las Investigaciones Lógicas para que sea posible en su fenomenología un diálogo entre filosofía y ciencia natural. Y en cuanto al existencialismo, la filosofía verdaderamente genuina del siglo XX, aunque inspirada en un muy anterior Soren Kierkegaard, aun siendo la más frontal respuesta que se ha dado al idealismo y a su punto de partida cartesiano -y una propuesta con la que profundamente empatizo-, no creo que aporte ningún elemento de diálogo con las ciencias, pues es algo absolutamente diferente.

Pero si bien la filosofía aristotélica parece adecuada para una epistemología científica actualizada y para una filosofía de la naturaleza según es ésta comprendida hoy por la ciencia, si ha de servir de base también a nuestras ideas actuales sobre la sociedad, esencialmente heredadas de la ilustración inglesa -Locke-, entonces Aristóteles sería insuficiente y habría que recurrir a su complemento en la filosofía aristotélico-tomista. En la teoría del estado de Locke, la sociedad humana, y por tanto las normas fundamentales de convivencia entre los hombres, son un hecho natural, de 
modo que la legislación de un estado, aun con procedimiento democrático impecable, podría ser injusta si no se "ajustase" a ellas. En la ilustración francesa -Rousseau- la justicia viene en cambio definida por el pacto con que se funde una sociedad, y no hay ley injusta si ha sido bien pactada, es decir si cuenta con los votos de la mayoría en la Asamblea en que el pueblo soberano se ha dado sus propias leyes (planteamiento relativista acerca de la justicia -para nada anterior al Estado- que indefectiblemente ha de llevar, y ha llevado, al totalitarismo). Por eso, cuando Nietzsche en la Genealogía de la Moral (Nietzsche 1972) ve como triunfo del sentido común cristiano los valores éticos de la Ilustración, y entiende la revolución francesa como la última revolución cristiana, revolución del vulgo y sus valores de igualdad contra la aristocracia, dice muy bien, pero dice muy bien mientras se refiera a la Ilustración de Locke y a los derechos del hombre. Si la filosofía que haya de dialogar con la ciencia ha de hacerlo también con este pensamiento social y si ha de entrar también en diálogo con el existencialismo y el personalismo del siglo XX, creo que ha de ir más allá del aristotelismo y situarse en las coordenadas aristotélico-tomistas de la filosofía medieval, precisamente la que gestó en su seno el embrión de la ciencia física. En efecto, la concepción de la persona y de la ley natural en Santo Tomás amplían la base aristotélica de modo que ha podido fundamentar el pensamiento de Francisco de Vitoria (De Vitoria 2007), inspiración inmediata de Hugo Grocio (Grocio 1925), y por esta vía, de lo mejor del pensamiento ilustrado.

En conclusión, para dialogar con la ciencia actual, parece que basta el pensamiento tan ceñido a la realidad de Aristóteles. Si además se pide, simultáneamente, dialogar con un pensamiento social que por encima de los colectivismos mire a la persona y a los derechos del hombre como realidades inalienables, entonces su complemento en la filosofía aristotélico-tomista parece adecuado. Al llegar aquí, y al recordar en mi madurez, después de tantas lecturas científicas y filosóficas, mi formación inicial en la filosofía de Aristóteles y de Santo Tomás, me parece comprender aquellos celebrados versos del poeta que entusiasmó mi juventud: "Y el final de toda exploración será llegar al punto de partida y conocerlo por primera vez". 


\section{Referencias}

Agazzi, E. 1978. Temas y problemas de filosofía de la física. Barcelona: Herder.

-. 1995. Filosofia della Natura. Scienza e Cosmologia. Casale Monferrato: Piemme. Arana, J. 2012. Los sótanos del universo. Madrid: Biblioteca nueva.

Aristóteles. 1970. Metafísica. Madrid: Gredos.

-. 1995. Física. Madrid: Gredos.

Artigas, M. 1985. Ciencia, Razón y Fe. Madrid: Libros MC.

-. 1992. El hombre a la luz de la Ciencia. Madrid: Libros MC.

-. 1995. La inteligibilidad de la naturaleza. Pamplona: Eunsa.

-. 1995. Filosofía de la naturaleza, Pamplona: Eunsa.

-. 1999. Filosofía de la Ciencia Experimental. Pamplona: Eunsa.

Bersanelli, M. 2012. “Origen y creación en el universo del Big Bang.” In Ciencia y religión en el siglo XXI: recuperar el diálogo, edited by E. Chuvieco, and D. Alexander, 61-93. Madrid: Editorial Centro de Estudios Ramón Areces.

Boyer, C.B. 1999. Historia de la Matemática. Madrid: Alianza Editorial.

Camacho, J.A., and I. Sols. 2009. “El proceso al copernicanismo y a Galileo.” Archivos Filosóficos del Sur 1.

-. 1994. “Domingo de Soto en el origen de la ciencia moderna." Revista de Filosofía 7(12):27-49.

-. 1995. "La Física de Domingo de Soto.” Revista Española de Física 9(4).

Chaitin, G. 1975. "Randomnes and Mathematical Proof.” Scientific American 232:

47-52. DOI: http://dx.doi.org/10.1038/scientificamerican0575-47

-. 2012. Proving Darwin, New York: Pantheon books.

Crombie. A.C. 1974. Historia de la Ciencia. Vol. 2. Madrid: Alianza.

Darwin, C. 1998. On the Origin of Species. New York: Oxford University Press.

Dawkins, R. 2010. El espejismo de Dios. Madrid: Espasa.

De Broglie, L. 1937. Matière et lumière. Paris: Editions Albin Michel.

Denzinger, H., and P. Hünermann. 1999. El magisterio de la Iglesia. Barcelona: Herder.

Descartes. R. 1986. Discurso del método. Madrid: Alfaguara.

De Vitoria, F. 2007. Sobre el poder civil, sobre los indios, sobre el derecho de guerra. Madrid: Tecnos.

Duhem, P. 1981. La théorie physique. Son objet. Sa structure, París: Vrin.

Einstein, A. 1983. Sobre la teoría de la relatividad, Madrid: Sarpe.

Euclides. 1991. Elementos. Madrid: Editorial Gredos.

Fantoli, A. 1997. Galileo. Per il Copernicanesimo e per la Chiesa. Vaticano: Librería Editrice Vaticana. 
Favaro, A., ed. 1968. Edizione nazionale delle Opere di Galileo Galilei. Florencia: Giunti Barbèra.

Gödel, K. 1931. “Über formal unentscheidbare Sätze der Principia Mathematica und verwandter Systeme I”. Monatshefte für Mathematik und Physik 38: 173-198. DOI: http://dx.doi.org/10.1007/BF01700692

Grocio, H. 1925. Sobre el derecho de la guerra y de la paz. Madrid: Editorial Reus.

Hawking, S.W. 1988. A Brief History of Time. London: Bantam Press.

-. 2010. El gran diseño. Barcelona: Crítica.

Heisenberg, W. 1976. La imagen de la naturaleza en la física actual. Barcelona: Ariel.

-. 1959. Física y Filosofía. Buenos Aires: Ediciones La Isla.

Hilbert, D. 1903. Grundlagen der Geometrie. Lepzig: B.G. Teubner.

Hume, D. 1981. Investigación sobre el conocimiento humano. Madrid: Alianza.

Husserl, E. 2006. Investigaciones lógicas. Madrid: Alianza Editorial.

Jaki, S.L. 1966. La ciencia y la fe. Pierre Duhem, Madrid: Encuentro.

Jordan, P. 1972. El hombre de ciencia ante el problema religioso. Madrid: Ediciones Guadarrama.

Kant, I. 1978. Crítica de la razón pura. Madrid: Alfaguara.

-. 1989. Principios metafísicos de la naturaleza. Madrid: Alianza.

Kauffman, S. 2003. Investigaciones. Complejidad, autoorganización y nuevas bases para una biología general. Barcelona: Tusquets.

-. 2009. "Five problems in the philosophy of mind." Visitada el 23 de agosto de 2013. www.edge.org/3rd_culture/kauffman09/kauffman09_index.html.

Kepler, J. 1937. Gesammelte Werke, Munich: Beck.

Kuhn, T. 2005. La estructura de las revoluciones científicas. México: Fondo de Cultura Económica.

Locke, J. 2005. Ensayo sobre el entendimiento humano. México: Fondo de Cultura Económica.

Martinez, R. 1995. La verità scientifica. Roma: Armando Editore, 1995.

-. 1996. Immagini del dinamismo fisico. Causa e tempo nella storia della scienza. Roma: Armando Editore 1996.

Monod, J. 1970. Le hasard et la nécessité. París: Éditions du Seuil.

Nietzsche, F. 1972. La genealogía de la moral. Madrid: Alianza Editorial.

Newton, I. 1845. Mathematical Principles of Natural Philosophy. Chicago: Great Books of Western World, Enclyclopaedia Britannica Inc.

Pascual, P., ed. 1984. Partículas elementales. Barcelona: Prensa científica.

Penrose, R. 1989. The Emperor's New Mind. London: Oxford University Press.

Poincaré, H. 1902. La Science et l'hypothèse. París: Flammarion.

Popper, K. 1967. El desarrollo del conocimiento científico, Buenos Aires: Paidós. 
-. 1986. El universo abierto. Madrid: Tecnos.

Schrödinger, E. 1958. Mente y materia. Madrid: Taurus.

-. 1975. ¿Qué es una ley de la naturaleza? México: F.C.E.

-. 1986. ¿Qué es la vida? El aspecto físico de la célula viva, Barcelona: Orbis.

Spinoza, B. 2005. Ética demostrada según el orden geométrico. Buenos Aires: Quadrata.

Sols, F. 2012. "Heisenberg, Gödel y la cuestión de la finalidad en ciencia.” In Ciencia y religión en el siglo XXI: recuperar el diálogo, edited by E. Chuvieco, and D. Alexander, 167-194. Madrid: Editorial Centro de Estudios Ramón Areces.

Sols, I. 2012. "Los dos sentidos del término "hipótesis” en la raíz del actual malentendido sobre el caso Galileo.” In Ciencia y religión en el siglo XXI: recuperar el diálogo, edited by E. Chuvieco, and D. Alexander, 33-60. Madrid: Editorial Centro de Estudios Ramón Areces.

Teilhard de Chardin, P. 1967. El fenómeno humano, Madrid: Taurus.

Tomas de Aquino. 1956. Suma Teológica. Madrid: BAC.

-. 1967. Suma contra los Gentiles, Madrid: BAC.

Turing, A. M. 1976. Maquinaria computadora e inteligencia. Controversia sobre Mentes y Máquinas. Barcelona: Ediciones Orbis.

Udías A. 2010. Ciencia y Religión. Dos visiones del mundo. Santander: Sal Terrae.

Weinberg, S. 1982. Los tres primeros minutos del universo. Una concepción moderna del origen del universo. Madrid: Alianza.

-. 1994. Dreams of a Final Theory, Nueva York: Vintage Books.

Wheeler, J.A. 1983. “Law without law.” In Quantum theory and measurement, edited by J.A. Wheeler, and W.H. Zurek, 182-213. Princeton: Princeton University Press. 